\title{
Wide Bite Angle Disphosphine Ligands in Thermally Activated Delayed Fluorescent Copper(I) Complexes: Impact on the Performance of Electroluminescence Applications
}

Chenfei Li, ${ }^{a}$ Campbell F. R. Mackenzie, ${ }^{a}$ Said A. Said, ${ }^{a}$ Amlan K. Pal, ${ }^{a, c}$ Mohammad A. Haghighatbin, ${ }^{b}$ Azin Babaei, ${ }^{d}$ Michele Sessolo, ${ }^{d}$ David B. Cordes, ${ }^{a}$ Alexandra M. Z. Slawin, ${ }^{a}$ Paul C. J. Kamer,${ }^{e \ddagger}$ Henk J. Bolink, ${ }^{d}$ Conor F. Hogan, ${ }^{b}$ Eli Zysman-Colman*,a

a) Organic Semiconductor Centre, EaStCHEM School of Chemistry, University of St Andrews, St Andrews, Fife, U.K., KY16 9ST, Fax: +44-1334 463808; Tel: +44-1334 463826; E-mail: eli.zysmancolman@st-andrews.ac.uk; URL: http://www.zysman-colman.com

${ }^{b)}$ Department of Chemistry \& Physics, La Trobe Institute for Molecular Science, La Trobe University, Melbourne, Victoria 3086, Australia.

c) Department of Chemistry, Indian Institute of Technology Jammu, Jagti Campus, Nagrota Bypass Road, Jammu \& Kashmir, 181221, India

d) Instituto de Ciencia Molecular, Universidad de Valencia, 46980 Paterna, Spain

e) Leibniz Institute for Catalysis, Albert-Einstein-Str. 29a, 18059 Rostock, Germany

Deceased November 19, 2020

This paper is dedicated to Professor Paul Kamer who passed away November 2020.

\footnotetext{
Abstract

We report a series of seven cationic heteroleptic copper(I) complexes of the form $\left[\mathrm{Cu}\left(\mathrm{P}^{\wedge} \mathrm{P}\right)\right.$ (dmphen) $\mathrm{BF}_{4}$, where dmphen is 2,9-dimethyl-1,10-phenanthroline and $\mathrm{P}^{\wedge} \mathrm{P}$ is a diphosphine chelate, in which the effect of the bite angle of the diphosphine ligand on the photophysical properties of the complexes was studied. Several of the complexes exhibit moderately high photoluminescence quantum yields in the solid-state, with $\Phi_{\mathrm{PL}}$ of up to $35 \%$, and in solution, with $\Phi_{\mathrm{PL}}$ of up to $98 \%$. We were able to correlate the powder photoluminescence quantum yields with the $\% \mathrm{~V}_{\text {bur }}$ of the $\mathrm{P}^{\wedge} \mathrm{P}$ ligand. The most
} 
emissive complexes were used to fabricate both organic light-emitting diodes (OLEDs) and lightemitting electrochemical calls (LECs), both of which showed moderate performance. Compared to the benchmark $\mathrm{Cu}(\mathrm{I})$-based LECs, $[\mathrm{Cu}(\mathrm{dnbp})(\mathrm{DPEPhos})]^{+}\left(\mathrm{EQE}_{\max }=16 \%\right)$, complex $3\left(\mathrm{EQE}_{\max }=1.85 \%\right)$ showed much longer device lifetime $\left(\mathrm{t}_{1 / 2}=1.25 \mathrm{~h}\right.$ and $>16.5 \mathrm{~h}$ for $[\mathrm{Cu}(\mathrm{dnbp})(\mathrm{DPEPhos})]^{+}$and complex 3 , respectively). The electrochemiluminescent properties of several complexes were also studied which to the best of our knowledge constitutes the first ECL study for heteroleptic copper (I) complexes. Notably, complexes exhibiting more reversible electrochemistry were associated with higher annihilation ECL as well as better performance in an LEC device.

\section{Introduction}

Improvements in the field of organic electronics underpin a wide range of developing technologies including organic light-emitting diodes (OLEDs), ${ }^{1,2}$ light-emitting electrochemical cells (LECs), ${ }^{3,4}$ organic photovoltaics (OPVs) ${ }^{5,6}$ and bio-/photo-sensors. ${ }^{7,8}$ Such developments have been central in our global efforts to move towards more energy-efficient processes as well as renewable and sustainable energy resources. There is a strong research effort in moving away from phosphorescent emitters based upon Iridium(III) and Platinum(II) to cheaper, more sustainable photoactive materials based on organic molecules ${ }^{9,10}$ and earth-abundant metals. ${ }^{11}$ Promising among the alternatives are $\mathrm{Cu}(\mathrm{I})$ complexes, which exhibit a desirable set of optoelectronic properties. ${ }^{12,13}$ Highly efficient $\mathrm{Cu}(\mathrm{I})$ emitters in electroluminescent devices operate via a TADF (Thermally Activated Delayed Fluorescence) mechanism. Prior to the use of the TADF moniker, ${ }^{14}$ this emission was known as E-type delayed fluorescence or as singlet harvesting, a process that has been studied in $\mathrm{Cu}(\mathrm{I})$ complexes since $1983 .{ }^{15}$ The first high-performance $\mathrm{Cu}(\mathrm{I})$ OLED using TADF was fabricated in $2004 .{ }^{16}$ Prominent amongst the $\mathrm{Cu}(\mathrm{I})$ complexes that have been investigated are cationic heteroleptic complexes of the type $[\mathrm{Cu}$ $\left.\left(\mathrm{P}^{\wedge} \mathrm{P}\right)\left(\mathrm{N}^{\wedge} \mathrm{N}\right)\right]^{+} \cdot{ }^{13,16-18} \mathrm{Cu}(\mathrm{I})$ complexes of this type have not only been studied as emitters for LECs and OLEDs, but also as cheaper, less toxic alternatives to photocatalysts based on iridium(III) and ruthenium(II) complexes. ${ }^{19-21}$ All these potential applications of $\mathrm{Cu}(\mathrm{I})$ complexes require a solid understanding of the relationship between structural design and optoelectronic properties.

Most previous studies into $\left[\mathrm{Cu}\left(\mathrm{P}^{\wedge} \mathrm{P}\right)\left(\mathrm{N}^{\wedge} \mathrm{N}\right)\right]^{+}$complexes have focused on modifying the diamine ligand. For example, Costa et al. studied how the electronic tuning of $4,4^{\prime}-\mathrm{R}_{2}$ bpy type of $\mathrm{N}^{\wedge} \mathrm{N}$ ligands could act on the solid-state photophysical and electroluminescent properties of $\left[\mathrm{Cu}(\mathrm{xantphos})\left(4,4^{\prime}-\right.\right.$ $\mathrm{R}_{2}$ bpy) $]^{+}$complexes. $^{22-26}$ More recently, Alkan-Zambada et al. reported a systematic study of heteroleptic $\mathrm{Cu}(\mathrm{I})$ complexes with differing $\mathrm{N}^{\wedge} \mathrm{N}$ ligands on the usefulness of percent volume buried as a predictor of photoluminescence quantum yield. They found that those heteroleptic $\mathrm{Cu}(\mathrm{I})$ complexes, which exhibited the highest solid state $\Phi_{\mathrm{PL}}$ also have higher $\% \mathrm{~V}_{\mathrm{Bur}} .{ }^{27}$ Only limited studies have focussed on the impact of the $\mathrm{P}^{\wedge} \mathrm{P}$ ligand on the structure and optoelectronic properties of 
$\left[\mathrm{Cu}\left(\mathrm{P}^{\wedge} \mathrm{P}\right)\left(\mathrm{N}^{\wedge} \mathrm{N}\right)\right]^{+}$complexes, with studies limited to DPEphos, xantphos and alkyl bridged bisdiphenylphosphino ligands. ${ }^{28}$ The exception to this limited collection of diphosphine ligands is a recent study by Housecroft et al. on the modification of the backbone of the xantphos ligand with tert-butyl groups for application in LECs. ${ }^{29}$

Our group has previously studied how changing the bite angle of diphosphine ligands could enhance the photoluminescence quantum yields $\left(\Phi_{\mathrm{PL}}\right)$ of blue-emitting cationic $\left[\operatorname{Ir}\left(\mathrm{C}^{\wedge} \mathrm{N}\right)_{2}\left(\mathrm{P}^{\wedge} \mathrm{P}\right)\right]^{+}$ complexes. ${ }^{30}$ More recently, we also demonstrated how the photophysical properties and photocatalytic reactivity can be systematically modulated by changing the electronics of $\mathrm{P}^{\wedge} \mathrm{P}$ ligands of $\left[\mathrm{Cu}\left(\mathrm{N}^{\wedge} \mathrm{N}\right)\left(\mathrm{P}^{\wedge} \mathrm{P}\right)\right]^{+}$complexes. ${ }^{31}$ Continuing these studies on a different series of $\left[\mathrm{Cu}\left(\mathrm{P}^{\wedge} \mathrm{P}\right)\left(\mathrm{N}^{\wedge} \mathrm{N}\right)\right]^{+}$ complexes, a library of eight diphosphine ligands (Scheme 1 and Table 1) was used to synthesise a family of seven emissive $\left[\mathrm{Cu}\left(\mathrm{P}^{\wedge} \mathrm{P}\right)(\mathrm{dmphen})\right] \mathrm{BF}_{4}$ complexes $1-7$, five of which are new (where dmphen=2,9-dimethyl-1,10-phenanthroline) A further complex $\left[\mathrm{Cu}(\mathrm{dppe})(\mathrm{dmphen}) \mathrm{BF}_{4}\right.$, where dppe $=$ [cis-1,2-(bis-(diphenylphosphino)ethylene], was non-emissive and it will not be discussed further, although the synthesis and characterisation of this complex is presented in the ESI. The complexes were fully characterized and their optoelectronic properties were determined. Selected complexes were used to fabricate OLEDs and LECs and investigate their electrochemiluminescent properties. A combination of theoretical calculations and an analysis of the molecular structure obtained from single crystal X-ray diffraction was used to rationalise the optoelectronic properties and device performance.<smiles>Pc1cccc(Pc2ccccc2Pc2ccccc2)c1P</smiles>

L1<smiles>CC1(C)c2cccc(P)c2Oc2c(P)cccc21</smiles>

L2<smiles>Pc1cccc(Pc2ccccc2)c1P</smiles>

L3<smiles>CC(C)=C1c2cccc(P)c2Oc2c(P)cccc21</smiles>

L4<smiles>Pc1cccc(Nc2ccccc2-c2cccc(P)c2P)c1</smiles>

L5<smiles>Pc1cccc2c1Oc1ccccc1S2</smiles><smiles>Pc1cccc(-c2ccccc2)c1-c1ccccc1</smiles>

L7

Scheme 1. Ligands studied in this work

Table 1. Calculated natural bite angles $\left(\beta_{\mathrm{n}}\right)$ and flexibility range for diphosphine ligands L1-L7. ${ }^{32,33}$

\begin{tabular}{lcc}
\hline & Natural bite angle, $\boldsymbol{\beta}_{\mathbf{n}}\left(^{\mathbf{0}}\right)^{\mathbf{a}}$ & Flexibility range $\left(^{\mathbf{0}}\right)^{\mathbf{b}}$ \\
\hline L1 & 102 & $86-120$ \\
L2 & 112 & $97-133$ \\
L3 & 102 & $92-120$ \\
L4 & 113 & $98-139$ \\
L5 & 114 & $99-141$
\end{tabular}


a) $\beta_{\mathrm{n}}$ is defined as the preferred chelation angle determined by the ligand backbone rigidity. ${ }^{\text {b) }}$ Flexibility range is defined as the accessible range of bite angles within $3 \mathrm{kcal} \mathrm{mol}^{-1}$ excess strain energy from the natural bite angle.

\section{Results and Discussion}

\section{Synthesis}

The $\left[\mathrm{Cu}\left(\mathrm{P}^{\wedge} \mathrm{P}\right)(\mathrm{dmphen})\right] \mathrm{BF}_{4}$ complexes were obtained through sequential ligand substitution of $\left[\mathrm{Cu}(\mathrm{NCMe})_{4}\right] \mathrm{BF}_{4}$ with diphosphine ligand $\mathbf{L 1}$ to $\mathbf{L} 7$ followed by 2,9-dimethyl-1,10-phenanthroline (dmphen) in a 1:1:1 ratio in dichloromethane (DCM) and/or acetonitrile $(\mathrm{MeCN})$, following protocols previously reported in the literature. ${ }^{18,34}$ Complexes $\mathbf{1}$ and $\mathbf{2}$ have been previously reported and our characterisation data match the known data. ${ }^{34,35}$ The formation of a small proportion $(2-10 \%$ of the crude product) of the homoleptic product $\left[\mathrm{Cu}(\mathrm{dmphen})_{2}\right] \mathrm{BF}_{4}{ }^{36}$ was evident by ${ }^{1} \mathrm{H}$ NMR. This byproduct proved difficult to remove by column chromatography, but purification could be achieved through recrystallisation from DCM/ether to afford orange/yellow/red crystals of heteroleptic complexes of $\left[\mathrm{Cu}\left(\mathrm{P}^{\wedge} \mathrm{P}\right)(\mathrm{dmphen}) \mathrm{BF}_{4}\right.$ in high yields (80-96\%) (Scheme 2). The identity of all complexes was confirmed by a combination of NMR, HRMS, elemental analysis and single crystal Xray diffraction.

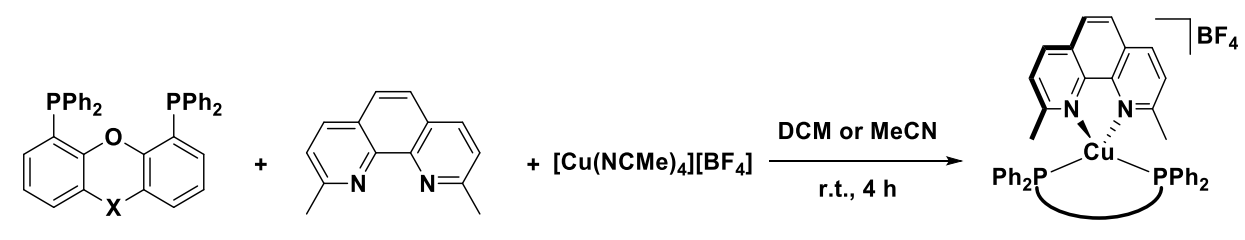

\begin{tabular}{llll} 
Complex & Ligand & $\begin{array}{l}\text { Common name of } \\
\text { the P^P ligand }\end{array}$ & Yield \\
\hline 1 & L1 & DPEphos; & $88 \%$ \\
2 & L2 & xantphos; & $87 \%$ \\
3 & L3 & homoxantphos; & $96 \%$ \\
4 & L4 & isopropxantphos; & $87 \%$ \\
5 & L5 & nixantphos; & $80 \%$ \\
6 & L6 & thixantphos; & $83 \%$ \\
7 & L7 & benzoxantphos; & $94 \%$
\end{tabular}

Scheme 2. Synthesis of $\left[\mathrm{Cu}\left(\mathrm{P}^{\wedge} \mathrm{P}\right)(\mathrm{dmphen})\right] \mathrm{BF}_{4}$ complexes 1-7.

\section{NMR Spectroscopy}

NMR spectra of all complexes are consistent with the proposed structures, see Figures S2-S19 for all spectra. The ${ }^{1} \mathrm{H}$ and ${ }^{13} \mathrm{C}$ spectra show signals corresponding to the dmphen and diphosphine ligand in a 1:1 ratio. In complexes 2 and $\mathbf{3}$, the methyl $(6 \mathrm{H}, 1.74 \mathrm{ppm})$ and methylene $(4 \mathrm{H}, 3.27 \mathrm{ppm})$ backbone substituents of the diphosphine ligands were identified. In complex $\mathbf{5}$, the amine proton of the nixantphos ligand is observed much further downfield at $7.37 \mathrm{ppm}$ than expected for an amine due to additional deshielding effects imposed by bridging between the two electron-withdrawing aryl groups. 
Complex 4 shows overlapping signals for methyl groups of both the dmphen ligand and the backbone of the isopropxantphos ligand in both the ${ }^{1} \mathrm{H}$ NMR (2.24 ppm, 12H) and ${ }^{13} \mathrm{C}$ NMR (23.4 ppm) spectra. The proton decoupled ${ }^{31} \mathrm{P}$ NMR spectra give rise to broad singlet peaks $(-10$ to $-17 \mathrm{ppm})$ for all complexes with the exception of 7 , which exhibits two singlet peaks ( $\sim 1: 1$ ratio) at -15.67 and -19.51 ppm due to the asymmetrical nature of the benzoxantphos ligand. The downfield resonance ( $-15.7 \mathrm{ppm})$ corresponds to the deshielded phosphorus attached to the more $\pi$-conjugated naphthalene moiety of the ligand in this complex. Of the symmetrical diphosphine ligands, 3 exhibits the most downfield signal at $-10.6 \mathrm{ppm}$. The ${ }^{19} \mathrm{~F}$ NMR spectra of all complexes show a characteristic $\mathrm{BF}_{4}{ }^{-}$multiplet at $c a .-150$ ppm, consistent with the presence of $\mathrm{BF}_{4}^{-}$counterion in all seven complexes.

\section{Single Crystal X-ray Characterisation}

Crystal structures of complexes 2-7 (Figure 1) were obtained from single crystal X-ray diffraction studies. All seven complexes exist as mononuclear species and exhibit a distorted tetrahedral environment around the $\mathrm{Cu}(\mathrm{I})$ metal centre in line with previously reported structures for complexes $\mathbf{1}$ and 2. ${ }^{18,35,37,38}$ Crystals of $\mathbf{1}$ showed a unit cell corresponding to one of the known structures. ${ }^{37}$ Crystals of $\mathbf{2}$ showed a unit cell similar to that seen in the known structure, but on determination of the structure, minor differences in the structure of the complex, and slight differences in packing were found. ${ }^{35}$ The average $\mathrm{Cu}-\mathrm{P}$ and $\mathrm{Cu}-\mathrm{N}$ bond lengths (Table $\mathrm{S1}$ ) are similar throughout the seven complexes, whereas the P-Cu-P bite angles vary between $110.58(3)^{\circ}$ and $121.25(8)^{\circ}$. Comparison of the $\mathrm{P}-\mathrm{Cu}-\mathrm{P}$ bite angle with the calculated natural bite angle of the ligands show that there are in excellent agreement for 2,4 , 5 and $7\left(<4^{\circ}\right.$ difference), while $\mathbf{3}$ and $\mathbf{6}$ have bite angles that are larger than expected by $9-12^{\circ} .32,33$ Despite the flexible nature of these diphosphine ligands, the bite angle in these complexes is still less than the $123^{\circ}$ seen between the two phosphorus ligands in $\left[\mathrm{Cu}\left(\mathrm{PPh}_{3}\right)_{2}(\mathrm{dmphen})\right]^{+} .^{38,39}$ The intramolecular distance between the two phosphorus atoms in the complexes correlates with the observed bite angles; the largest values for both exist in $7\left(4.00 \AA, 121^{\circ}\right)$. In complexes $2-7$, the backbone of the $\mathrm{P}^{\wedge} \mathrm{P}$ ligand adopts a bent conformation, producing a "butterfly-type" structure. ${ }^{40}$ The angle between these backbone phenyl rings reflects the flexibility of the linker, with 7 possessing the smallest angle of $17.2^{\circ}$, reflecting the rigidity of the naphthyl linker, 5 and $\mathbf{6}$ having intermediate angles of $29.1^{\circ}$ and $23.7^{\circ}$, respectively, and 2-4 showing angles between $44.7-49.2^{\circ}$. The flexibility of the DPEphos ligand in $\mathbf{1}$ is illustrated by the torsions seen between the two ether bridged phenyl rings in the known structures of this complex $\left(72.6-76.0^{\circ}\right) .^{18,37,38}$

The structures reveal intramolecular $\pi-\pi$ interactions for complexes 3, 6 and 7 (see Figure S21), with centroid $\cdots$ centroid distances ranging from 3.664(5) to 3.7145(17) $\AA$. The structures of these three complexes reveal a linear chains of cations (running along the $a$-axis for 3 and the $\left[\begin{array}{lll}0 & 1 & -1\end{array}\right]$ axis for 6 and 7) showing $\pi-\pi$ interactions between the dmphen and one of the aromatic rings of the phosphine 
ligands of adjacent cations (one of the peripheral phenyls for $\mathbf{3}$, one of the aromatic rings of the ligand backbone for $\mathbf{6}$ and 7$)$.

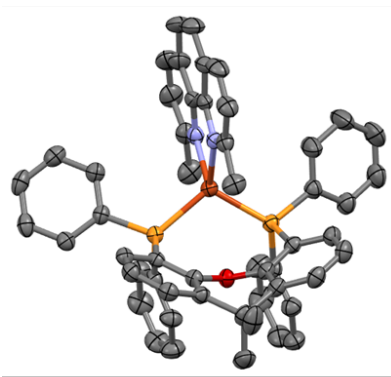

2

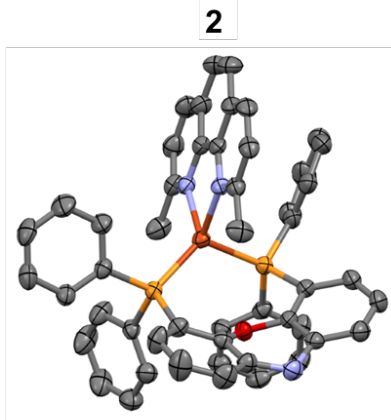

5

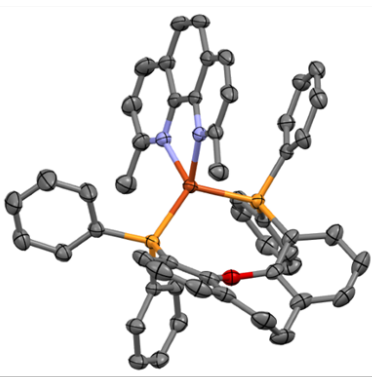

3

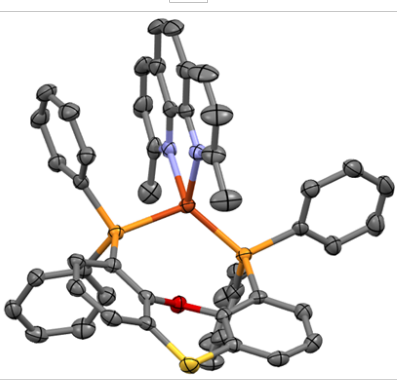

6

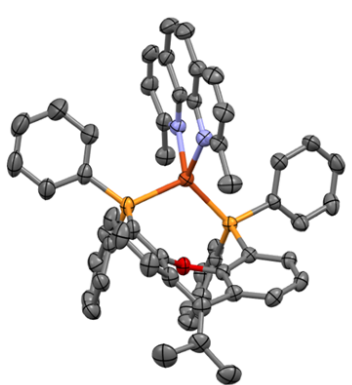

4

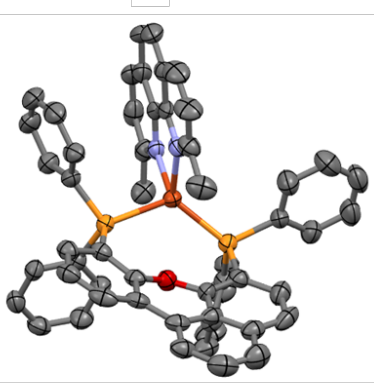

7

Figure 1. Thermal ellipsoid plots of the crystal structures of complexes 2-7. Ellipsoids are drawn at the $50 \%$ probability level and hydrogen atoms, solvents and anions are omitted for clarity.

\section{Theoretical Studies}

The structure and electronic properties of all cations were calculated using DFT and TD-DFT methods. Calculations were performed using the B3LYP functional with 6-31G(d,p) (for C, H, N, O, P and $\mathrm{S}$ atoms) and SBKJC VDZ ECP (for $\mathrm{Cu}$ ) basis sets with a Polarizable Continuum Model of dichloromethane solvent using Gaussian 09. ${ }^{41-48}$ Ground state geometries were optimised starting from the structures determined experimentally by X-ray Crystallography. Notably the calculated P-Cu-P bite angles are within $4^{\circ}$ of the experimental values. Figure 2 shows the HOMO and LUMO electron density distribution and energies for each cation along with the contribution to the frontier molecular orbitals. The calculated electronic properties are shown in Table 2.

The energy of the LUMO for all complexes lies in a narrow range between -2.22 and $-2.27 \mathrm{eV}$, the similarity is expected as in all cases the LUMO is localised on the dmphen ligand. The HOMO energies for complexes 1-4 and 6 lie within a narrow range of -5.81 to $-5.97 \mathrm{eV}$, in these complexes the HOMO is distributed between the $\mathrm{Cu}$ atom and the diphosphine ligand. Relative to these complexes, $\mathbf{5}$ and 7 have a slightly destabilised HOMO (-5.60 and $-5.73 \mathrm{eV}$ respectively) that is localised on the 
diphosphine ligand. Except for complex 6 the very similar HOMO and LUMO levels result in HOMOLUMO gaps within a narrow range $\Delta \mathrm{E}=3.51$ to $3.69 \mathrm{eV}$. For complex $6 \Delta \mathrm{E}=3.37 \mathrm{eV}$, with the lower bandgap reflecting the destabilised HOMO.

TD-DFT calculations were performed to obtain information on the excited state energy levels of complexes 1-7. The energy levels of the $S_{1}$ excited state were similar for 1, 2, 4, 6 and 7 with $E_{S 1}=$ 3.01-3.04 eV, complexes 3 and 5 had slightly lower $S_{1}$ energies $\left(E_{S 1}=2.88 \mathrm{eV}\right.$ and $2.94 \mathrm{eV}$ respectively). Complexes 1-6 all had very similar triplet energies with $\mathrm{E}_{\mathrm{T} 1}=2.68$ to $2.79 \mathrm{eV}$, resulting in each of these complexes exhibiting a moderate $\Delta \mathrm{E}_{\mathrm{st}}$ of 0.16 to $0.28 \mathrm{eV}$, suggesting promise as TADF emitters. In contrast complex 7 has a much lower triplet energy $\left(\mathrm{E}_{\mathrm{T} 1}=2.29 \mathrm{eV}\right)$ which results in a much larger $\Delta \mathrm{E}_{\mathrm{ST}}$ of $0.73 \mathrm{eV}$. The triplet spin density of 7 is localised on the benzoxantphos ligand, suggesting that a low-lying ligand-centred triplet state is responsible for the larger calculated $\Delta \mathrm{E}_{\mathrm{ST}}$. In contrast complexes 1-6 show a triplet spin density distributed across the dmphen ligand and $\mathrm{Cu}$ centre, pointing to an MLCT triplet excited state.

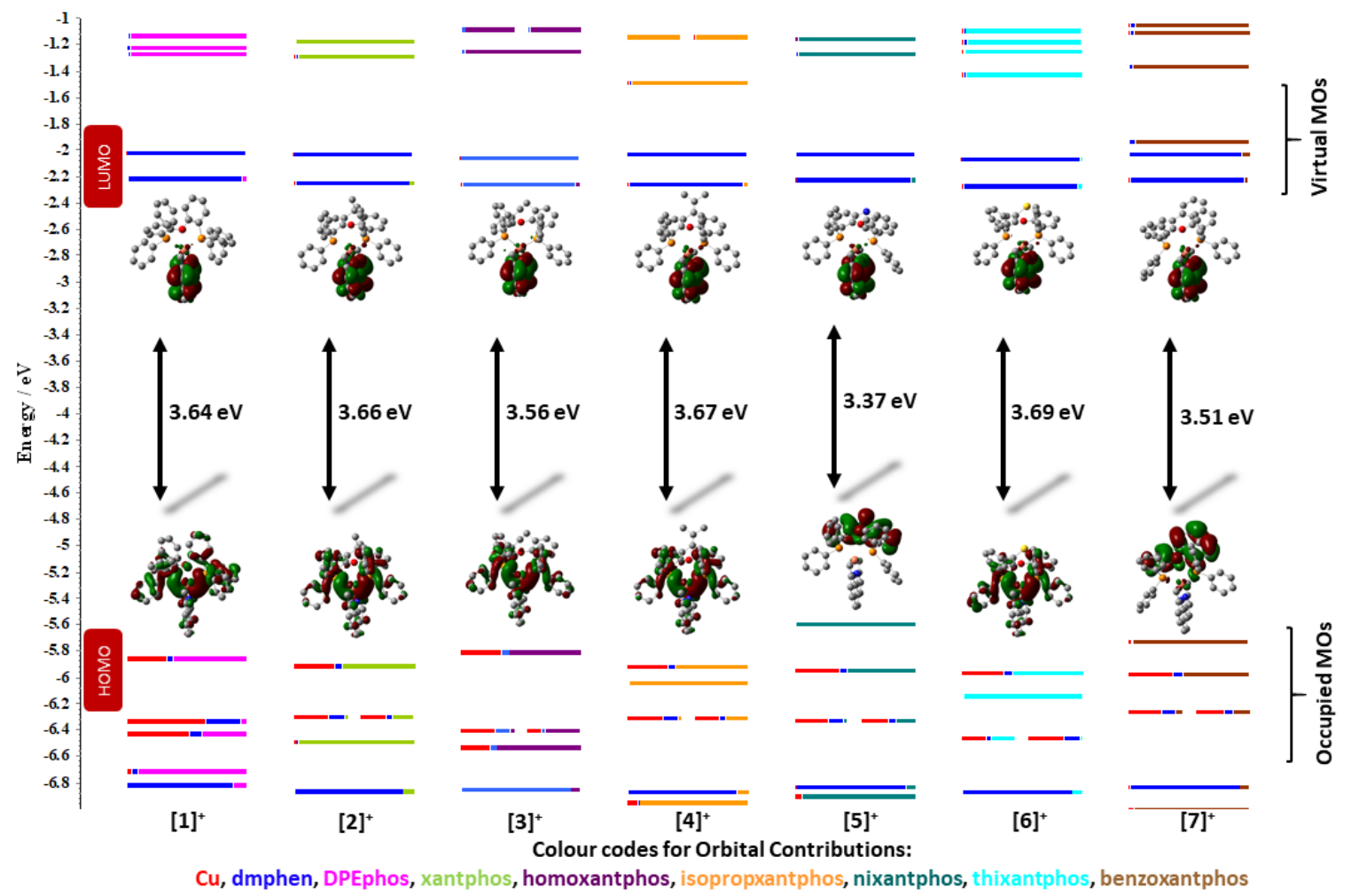

Figure 2. DFT calculated frontier MO energies of $[1]^{+}-[7]^{+}$. Kohn-Sham MOs of $[1]^{+}-[7]^{+}$are also shown. 
Table 2. DFT calculated electronic properties of complexes $[\mathbf{1}]^{+}$to $[7]^{+}$.

\begin{tabular}{ccccccc}
\hline & $\mathbf{H O M O} / \mathbf{e V}$ & $\mathbf{L U M O} / \mathbf{e V}$ & $\mathbf{\Delta E} / \mathbf{e V}$ & $\mathbf{S}_{\mathbf{1}} / \mathbf{e V}$ & $\mathbf{T}_{\mathbf{1}} / \mathbf{e V}$ & $\Delta \mathbf{E}_{\mathbf{S T}} / \mathbf{e V}$ \\
\hline $\mathbf{1}$ & -5.86 & -2.22 & 3.64 & 3.01 & 2.78 & 0.23 \\
$\mathbf{2}$ & -5.91 & -2.25 & 3.66 & 3.03 & 2.76 & 0.27 \\
$\mathbf{3}$ & -5.81 & -2.26 & 3.56 & 2.88 & 2.68 & 0.21 \\
$\mathbf{4}$ & -5.93 & -2.26 & 3.67 & 3.04 & 2.76 & 0.28 \\
$\mathbf{5}$ & -5.60 & -2.23 & 3.37 & 2.94 & 2.79 & 0.16 \\
$\mathbf{6}$ & -5.97 & -2.27 & 3.69 & 3.04 & 2.79 & 0.25 \\
$\mathbf{7}$ & -5.73 & -2.23 & 3.51 & 3.02 & 2.29 & 0.73 \\
\hline
\end{tabular}

\section{Electrochemical properties}

The electrochemical properties of complexes 1-7 were studied by cyclic voltammetry (CV) and differential pulse voltammetry (DPV) in degassed DCM (Figure 3 and Table 3). In order to facilitate study of the electrochemiluminescence (ECL) properties, vide infra, the voltammetry of complexes $\mathbf{1}$, 2, 3, 5 and $\mathbf{6}$ were also examined in acetonitrile. In the CV measurements, irreversible reduction waves were observed for all seven complexes in DCM, the DPV measurements more clearly show these reduction waves that all have very similar reduction potentials ranging from -1.7 to $-1.8 \mathrm{~V}$. The similar reduction potentials between the complexes and the irreversible nature is consistent with a ligandcentred reduction of dmphen, which is supported by the DFT calculations. The reduction potential of 2 is measured to be $0.24 \mathrm{~V}$ more negative than the literature value $(-1.48 \mathrm{~V}$ vs SCE in MeCN$),{ }^{49}$ it is believed that this difference can be attributed to the different solvent used. 


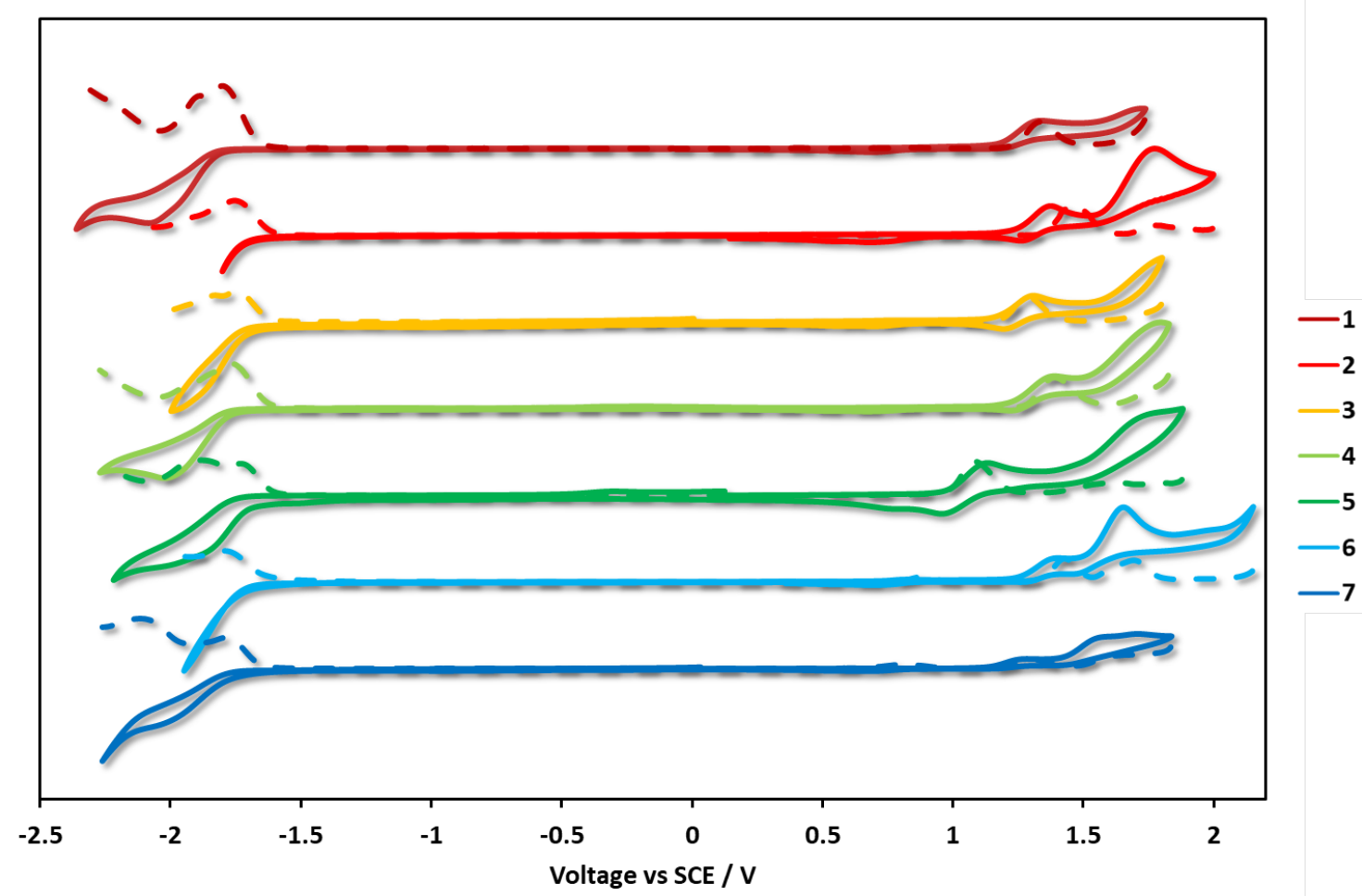

Figure 3. CV traces of 1-7 measured in degassed DCM vs. SCE. ${ }^{50}$ Scan rate: $50 \mathrm{mV} \mathrm{s}^{-1}$, initial scan was in the positive direction. DPV traces of each complex recorded in the same cell are overlaid in dashed lines.

The first oxidation potentials of $\mathbf{1}$ to 7 vary more widely within the range of $1.10-1.49 \mathrm{~V}$. The oxidation waves for complexes $\mathbf{2}, \mathbf{3}, \mathbf{5}$ showed quasi-reversible character, while the remaining complexes exhibited irreversible oxidations. The oxidation potential of complex $\mathbf{2}$ is in good agreement with previously reported values in $\mathrm{MeCN}\left(1.49 \mathrm{~V}\right.$ and $1.45 \mathrm{~V}$ respectively) ${ }^{51}$ however the oxidation potential of complex 1 is $240 \mathrm{mV}$ lower than previously reported in $\mathrm{MeCN}(1.35 \mathrm{~V}$ and $1.59 \mathrm{~V}$ respectively). ${ }^{34,51}$ Good consistency between the HOMO energy level determined by electrochemistry and the HOMO energy level from DFT prediction was observed, with the calculated values consistently lower by ca. $0.3 \mathrm{eV}$. Complex 5 had the most cathodically shifted oxidation potential $(1.10 \mathrm{~V})$ and most destabilised HOMO energy $(-5.30 \mathrm{eV})$ due to its strongly electron-donating nixantphos ligand. The remaining six complexes exhibited very similar oxidation potentials. In acetonitrile, the redox potentials were found to be similar, differing by no more than $100 \mathrm{mV}$ between solvents. In general, the oxidation processes were slightly less positive while the reduction processes were slightly less negative. Interestingly, the first reduction process for each complex measured, with the exception of $\mathbf{5}$, was chemically reversible in $\mathrm{CH}_{3} \mathrm{CN}$, suggesting that the reduced form of those complexes is more electrochemically stable in acetonitrile than in DCM. See Figure S22 in supporting information. 
Table 3. Electrochemistry data of complexes of complexes 1-7

\begin{tabular}{ccccccccc}
\hline Complex & $\begin{array}{c}\mathbf{E}_{\mathbf{o x}} \\
{[\mathrm{V}]^{\mathrm{a}}}\end{array}$ & $\begin{array}{c}\mathbf{E}_{\text {red }} \\
{[\mathrm{V}]^{\mathrm{a}}}\end{array}$ & $\begin{array}{c}\Delta \mathbf{E}_{\text {redox }} \\
{[\mathrm{V}]^{\mathrm{a}}}\end{array}$ & $\begin{array}{c}\mathbf{E}_{\text {opt }} \\
{[\mathrm{eV}]^{\mathrm{b}}}\end{array}$ & $\begin{array}{c}\mathbf{E}_{\mathbf{0 x}} \\
{[\mathrm{V}]^{\mathrm{c}}}\end{array}$ & $\begin{array}{c}\mathbf{E}_{\text {red }} \\
{[\mathrm{V}]^{\mathrm{c}}}\end{array}$ & $\begin{array}{c}\text { HOMO } \\
{[\mathrm{eV}]^{\mathrm{d}}}\end{array}$ & $\begin{array}{c}\mathbf{L U M O} \\
{[\mathrm{eV}]^{\mathrm{d}}}\end{array}$ \\
\hline $\mathbf{1}$ & 1.35 & -1.79 & 3.14 & 2.70 & -1.35 & 0.91 & -5.53 & -2.51 \\
$\mathbf{2}$ & 1.49 & -1.72 & 3.21 & 2.84 & -1.35 & 1.12 & -5.57 & -2.64 \\
$\mathbf{3}$ & 1.31 & -1.73 & 3.04 & 2.63 & -1.32 & 0.90 & -5.51 & -2.63 \\
$\mathbf{4}$ & 1.41 & -1.74 & 3.15 & 2.71 & -1.30 & 0.97 & -5.57 & -2.51 \\
$\mathbf{5}$ & 1.10 & -1.71 & 2.81 & 2.85 & -1.75 & 1.14 & -5.30 & -2.64 \\
$\mathbf{6}$ & 1.45 & -1.76 & 3.21 & 2.91 & -1.46 & 1.15 & -5.60 & -2.64 \\
$\mathbf{7}$ & 1.27 & -1.77 & 3.14 & 3.08 & -1.35 & 0.91 & -5.53 & -2.51 \\
\hline
\end{tabular}

a) Electrochemistry recorded in DCM solution with $0.1 \mathrm{M}\left({ }^{\mathrm{n}} \mathrm{Bu}_{4} \mathrm{~N}\right) \mathrm{PF}_{6}$ at $298 \mathrm{~K}$ at $50 \mathrm{mV} \cdot \mathrm{s}^{-1}$, $\mathrm{E}_{\mathrm{p}}$ were determined from the peak value of DPV traces, values are in $\mathrm{V}$ vs. SCE ( $\mathrm{Fc} / \mathrm{Fc}^{+}$vs. $\mathrm{SCE}=0.46 \mathrm{~V} .{ }^{52 \mathrm{~b})}$ Optical gap inferred from the intersection points of the normalised absorption and emission spectra in DCM. ${ }^{\mathrm{c}}$ Excited state redox potentials calculated with equation $\mathrm{E}^{*}{ }_{\mathrm{ox}}=\mathrm{E}_{\mathrm{ox}}-\mathrm{E}_{\mathrm{opt}}, \mathrm{E}^{*}{ }_{\text {red }}=\mathrm{E}_{\mathrm{red}}+\mathrm{E}_{\mathrm{op} .{ }^{53}}{ }^{53)}$ Calculated according to equations: $\mathrm{E}_{\mathrm{HOMO}}=$ $-\left(\mathrm{E}_{[\mathrm{onset}, \mathrm{ox} \text { vs. } \mathrm{Fc}+/ \mathrm{Fc}]}+4.8\right)(\mathrm{eV})$ and $\mathrm{E}_{\mathrm{LUMO}}=-\left(\mathrm{E}_{[\text {onset, red vs. } \mathrm{Fc}+/ \mathrm{Fc}]}+4.8\right)(\mathrm{eV}){ }^{49}$

Photocatalysis employing heteroleptic $\mathrm{Cu}(\mathrm{I})$ complexes as photocatalysts is a growing field of research. ${ }^{19-21,54}$ We thus assessed the excited state redox potentials of complexes 1-7. The $\mathrm{E}^{*}$ ox value of complex $2\left(-1.50 \mathrm{~V}\right.$ vs SCE in DCM) is slightly more negative than literature value ( $\mathrm{E}^{*}{ }_{\mathrm{ox}}=-1.19 \mathrm{~V}$ vs $\mathrm{SCE}$ in $\mathrm{MeCN})$ due to the larger $\mathrm{E}_{0,0}$ resulting from solvatochromism $\left(\mathrm{E}_{0,0}=2.84\right.$ and $2.64 \mathrm{eV}$ in DCM and $\mathrm{MeCN}$, respectively). ${ }^{49}$ Complexes 5 and 7 show very negative excited state oxidation potentials $\left(\mathrm{E}^{*}{ }_{\mathrm{ox}}=-1.83 \mathrm{~V}\right.$ for $\mathbf{5},-1.85 \mathrm{~V}$ for 7 ), values that are more negative than that of previously reported complexes 1 and $\mathbf{2}$, as well as the commonly used strong photoreductant $f a c-\operatorname{Ir}(\mathrm{ppy})_{3}\left(\mathrm{E}^{*}{ }_{\mathrm{ox}}=-1.73 \mathrm{~V}\right.$ vs SCE in MeCN). ${ }^{55}$ These complexes are potentially stronger photoreductants than the well-studied homoleptic $\mathrm{Cu}(\mathrm{I})$ photocatalyst $\left[\mathrm{Cu}(\mathrm{dap})_{2}\right] \mathrm{Cl}\left(\mathrm{E}^{*}{ }_{\text {ox }}=-1.43 \mathrm{~V}\right) .{ }^{56}$ The complexes are weaker photoreductants than homoleptic $\left[\mathrm{Cu}\left(\mathrm{P}^{\wedge} \mathrm{P}\right)_{2}\right]^{+}$complexes $\quad\left(\right.$ e.g. $\mathrm{E}^{*}{ }_{\mathrm{ox}}=-2.34 \mathrm{~V}$ for $\left.\left[\mathrm{Cu}(\mathrm{DPEphos})_{2}\right] \mathrm{BF}_{4}\right),{ }^{57}$ however $\left[\mathrm{Cu}\left(\mathrm{P}^{\wedge} \mathrm{P}\right)_{2}\right]^{+}$complexes have very poor visible light absorption in comparison to complexes 1-7. The excited state reduction potentials of complexes 1,4 and 5 lie in the range of $0.62-0.83 \mathrm{~V}$, values that are similar to the widely used photocatalyst $\left[\mathrm{Ru}(\mathrm{bpy})_{3}\right]^{2+}\left(\mathrm{E}^{*}{ }_{\text {red }}=\right.$ $0.77 \mathrm{~V}),{ }^{58}$ but lower than some $\left[\mathrm{Cu}\left(\mathrm{N}^{\wedge} \mathrm{N}\right)(\mathrm{NHC})\right]^{+}$photocatalysts $\left(\right.$e.g. $\mathrm{E}^{*}{ }_{\text {red }}=1.52 \mathrm{~V}$ for $\left.[\mathrm{Cu}(\mathrm{SIPr})(\mathrm{bpy})] \mathrm{PF}_{6}\right) .{ }^{59}$ As a result, these complexes are most promising for use as photocatalysts in reactions that proceed via oxidative quenching pathways.

\section{UV-Visible absorption}

UV-Vis absorption spectra of 1-7 were recorded in DCM solution, the absorption spectra are shown in Figure 4 while the data is collated in Table 4. The UV-Vis absorption spectra of complexes 1-6 exhibit broad, low-intensity absorption bands with $\lambda_{\text {abs }}$ between $380-400 \mathrm{~nm}\left(2 \times 10^{-3}<\varepsilon<5 \times 10^{-3}\right.$ 
$\mathrm{M}^{-1} \mathrm{~cm}^{-1}$ ) in DCM, which can be attributed to metal-ligand charge transfer (MLCT) transitions from the copper to the $\pi$-accepting dmphen. ${ }^{18}$ Complex 7 showed a more intense absorption at higher energy ( $\varepsilon$ $=11.3 \times 10^{-3} \mathrm{M}^{-1} \mathrm{~cm}^{-1}$ at $363 \mathrm{~nm}$ ) attributed to a ligand centred transition within the benzoxantphos ligand. At higher energy, all complexes exhibited intense absorption bands between 250-275 nm ( $\varepsilon=$ $30-45 \times 10^{3} \mathrm{M}^{-1} \mathrm{~cm}^{-1}$ ) attributed to a mixture of $\mathrm{N}^{\wedge} \mathrm{N}$ and $\mathrm{P}^{\wedge} \mathrm{P}$ ligand-centred $\pi-\pi^{*}$ transitions. These are similar to those reported for $\left[\mathrm{Cu}\left(\mathrm{P}^{\wedge} \mathrm{P}\right)\left(\mathrm{N}^{\wedge} \mathrm{N}\right)\right]^{+}$type complexes, such as $[\mathrm{Cu}(\mathrm{Xantphos})($ bpy $)] \mathrm{BF}_{4}$ and its derivatives ${ }^{25}$ or $\left[\mathrm{Cu}(\right.$ Xantphos $)(\mathrm{dmphen}) \mathrm{BF}_{4}{ }^{49}$

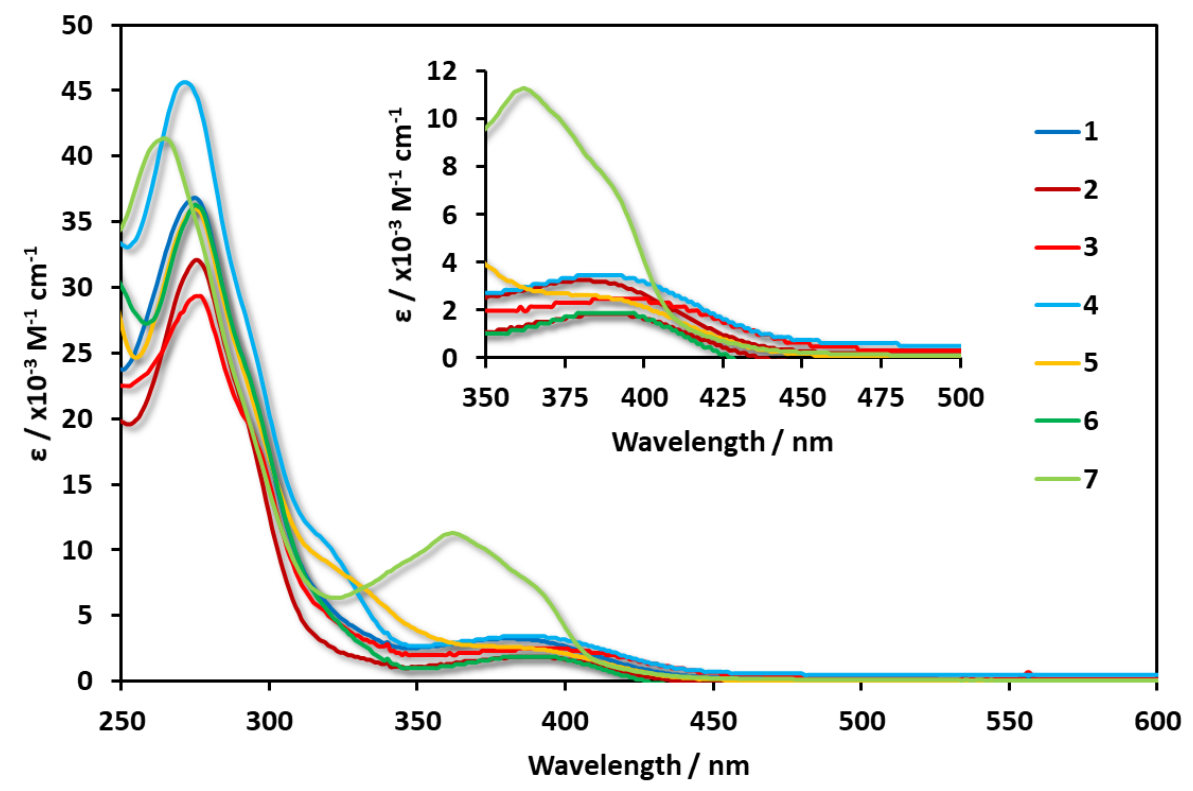

Figure 4. UV-Vis spectra of complexes 1-7 in DCM at room temperature.

Table 4. Experimental and calculated absorption data for 1-7

\begin{tabular}{|c|c|c|c|c|c|}
\hline & \multicolumn{2}{|c|}{$\lambda / \mathrm{nm}\left(\varepsilon \times 10^{-3} / \mathrm{M}^{-1} \mathrm{~cm}^{-1}\right)^{\mathrm{a}}$} & \multirow{2}{*}{$\begin{array}{c}\text { Calculated } \\
\lambda / \mathrm{nm}(f)^{\mathrm{b}}\end{array}$} & \multirow{2}{*}{ Contributions } & \multirow{2}{*}{ Nature $^{b}$} \\
\hline & $\mathrm{LC}$ & $\mathrm{CT}$ & & & \\
\hline 1 & $276(37)$ & $379(3.3)$ & $412(0.110)$ & $\mathrm{H} \rightarrow \mathrm{L}(97 \%)$ & MLCT/LLCT \\
\hline 2 & $277(32)$ & $391(1.9)$ & $409(0.138)$ & $\mathrm{H} \rightarrow \mathrm{L}(98 \%)$ & MLCT/LLCT \\
\hline 3 & $277(28)$ & $396(2.5)$ & $430(0.093)$ & $\mathrm{H} \rightarrow \mathrm{L}(96 \%)$ & MLCT/LLCT \\
\hline 4 & $272(46)$ & $386(3.6)$ & $408(0.143)$ & $\mathrm{H} \rightarrow \mathrm{L}(98 \%)$ & MLCT/LLCT \\
\hline 5 & $277(36)$ & $385(2.6)$ & $408(0.083)$ & $\mathrm{H}-1 \rightarrow \mathrm{L}(88 \%)$ & MLCT/LLCT \\
\hline 6 & $277(36)$ & $391(1.9)$ & $408(0.111)$ & $\mathrm{H} \rightarrow \mathrm{L}(95 \%)$ & MLCT/LLCT \\
\hline 7 & $264(41)$ & $363(11.3)$ & $376(0.244)$ & $\mathrm{H}-1 \rightarrow \mathrm{L}+1(34 \%) \mathrm{H} \rightarrow \mathrm{L}+2(54 \%)$ & LC, MLCT/LLCT \\
\hline
\end{tabular}

For complexes 1-4 and 6, the lowest energy absorbance band matches well the lowest energy transition in the TD-DFT calculated absorption spectra, corresponding to a HOMO to LUMO transition that is of mixed metal-to-ligand and $\mathrm{P}^{\wedge} \mathrm{P}$ to $\mathrm{N}^{\wedge} \mathrm{N}$ ligand-to-ligand charge transfer (MLCT/LLCT) character. For complex 5, the calculated lowest energy transition ( $421 \mathrm{~nm}, f=0.003$ ) corresponds to a LLCT $\left(\mathrm{P}^{\wedge} \mathrm{P}->\mathrm{N}^{\wedge} \mathrm{N}\right)$ transition from the HOMO localised on the electron-donating phenoxazine backbone of nixantphos. The next lowest energy (408 $\mathrm{nm}, f=0.083$ ) transition is mainly MLCT in 
character (HOMO-1 to LUMO) and is expected to be responsible for the observed CT band in the experimental spectrum. For complex 7 the TD-DFT calculations predict that the transition to $\mathrm{S}_{6}$ is the first transition with a significant $(f>0.1)$ oscillator strength and is predominately a ligand centred transition localised on the benzoxantphos ligand ( $\lambda_{\text {abs }}=377 \mathrm{~nm}, f=0.244,54 \%$ HOMO to LUMO +2$)$.

\section{Photophysics}

The emission properties of complexes 1-7 were measured in DCM solution (Figure 6) and in the solid state as both powders and spin-coated neat films (Table 5). The solution-state emission spectra of 1-6 are broad and unstructured with maxima, $\lambda_{\mathrm{PL}}$, ranging from $540-570 \mathrm{~nm}$; characteristic of originating from an emissive CT state. Complex 7 exceptionally shows a weak, blue, structured emission at $431 \mathrm{~nm}\left(\Phi_{\mathrm{PL}}<1 \%\right)$. The emission spectrum of $\mathbf{7}$ is similar to that of $\mathbf{L} \mathbf{7}$, suggesting a ligand centred emission, consistent with our TD-DFT calculations. Amongst complexes 1-6, 3 exhibited the most red-shifted emission profile $\left(\lambda_{\mathrm{em}}=567 \mathrm{~nm}\right)$. Complexes 1-3 and 6 are all strongly emissive in $\operatorname{DCM}\left(\Phi_{\mathrm{PL}}\right.$ from 40 to $98 \%$ ) while the remaining three complexes are almost non-emissive.

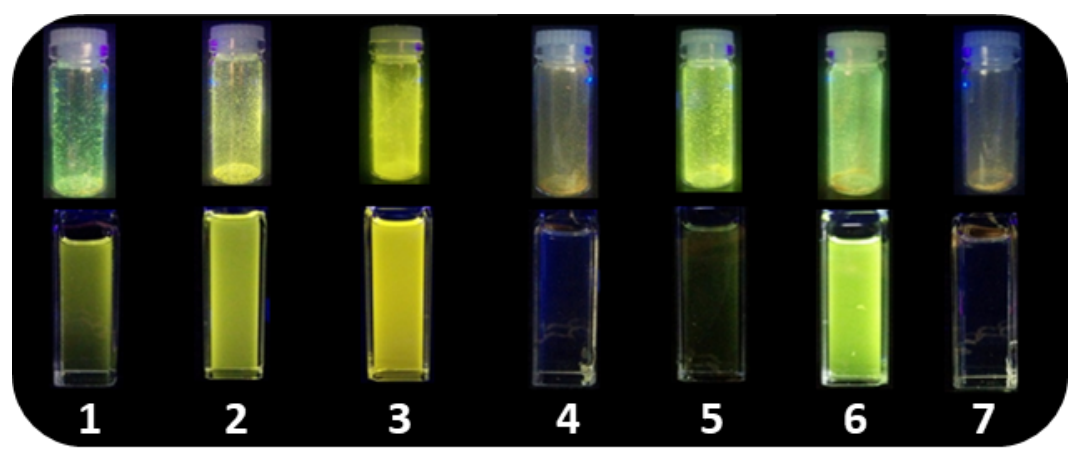

Figure 5. Pictures showing the emission from the complexes 1-7 (left to right) in the solid state (top row) and as DCM solutions (bottom row). 


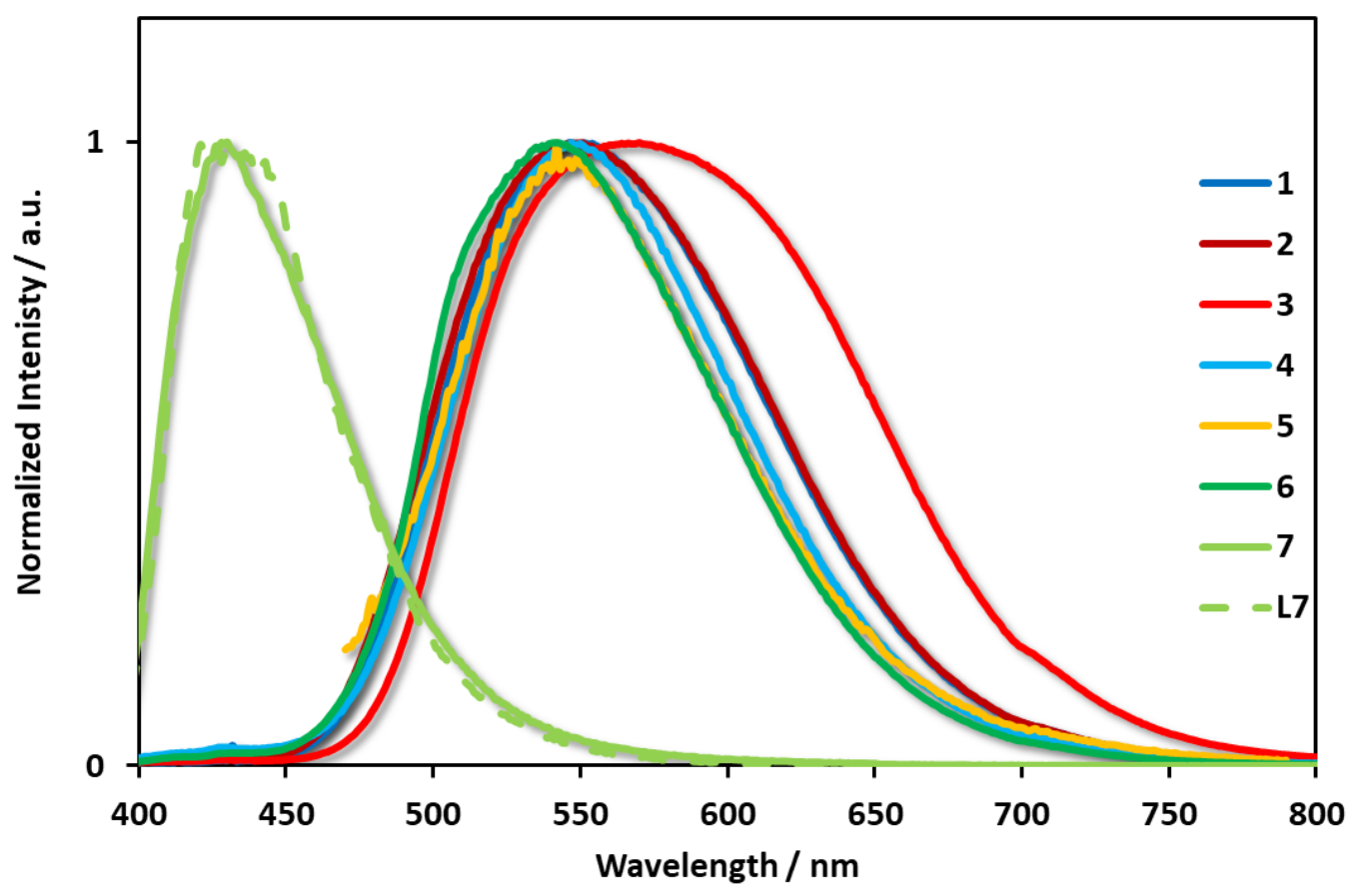

Figure 6. Normalised emission profile of complex 1-7 and L7 in degassed, dilute (ca. 10 $\left.{ }^{-5} \mathrm{M}\right)$ DCM solution, $\lambda_{\mathrm{exc}}=380 \mathrm{~nm}$.

Table 5. Photophysical properties of complexes 1-7 in DCM solution, as powders and spin-coated neat films.

\begin{tabular}{|c|c|c|c|c|c|c|}
\hline \multirow[b]{2}{*}{ Complex } & \multicolumn{2}{|c|}{$\mathbf{D C M}^{\mathbf{a}}$} & \multicolumn{4}{|c|}{ Solid State } \\
\hline & $\begin{array}{c}\lambda_{\mathrm{PL}} / \\
\mathrm{nm}\end{array}$ & $\Phi_{\mathrm{PL}}^{\mathrm{b}} / \%$ & $\lambda_{\mathrm{PL}} / \mathrm{nm}$ & $\begin{array}{r}\text { Powc } \\
\Phi_{P L}{ }^{c} / \%\end{array}$ & $\tau / \mathrm{ns}^{\mathrm{d}}$ & $\begin{array}{l}\text { Thin Film } \\
\Phi_{\mathrm{PL}^{c}}{ }^{\mathrm{c}} \%\end{array}$ \\
\hline 1 & 550 & 71 & 530 & 14 & $\begin{array}{c}838(8 \%) \\
3030(48 \%) \\
9420(44 \%)\end{array}$ & 14 \\
\hline 2 & 549 & 40 & 552 & 11 & $\begin{array}{c}38(3 \%) \\
2350(45 \%) \\
7560(52 \%) \\
723(5 \%)\end{array}$ & 28 \\
\hline 3 & 567 & 60 & 543 & 35 & $\begin{array}{c}3980(25 \%) \\
12200(72 \%) \\
1.0(61 \%)\end{array}$ & 24 \\
\hline 4 & 547 & $<1$ & 579 & 1 & $\begin{array}{l}6.4(29 \%) \\
40(10 \%) \\
797(2 \%)\end{array}$ & $<1$ \\
\hline 5 & 543 & 1 & 577 & 18 & $\begin{array}{c}4560(38 \%) \\
14200(60 \%) \\
1000(5 \%)\end{array}$ & 2 \\
\hline 6 & 541 & 98 & 548 & 17 & $\begin{array}{c}4840(44 \%) \\
16200(51 \%) \\
1.0(49 \%)\end{array}$ & 6 \\
\hline 7 & 431 & $<1$ & 430 & $<1$ & $\begin{array}{l}5.7(36 \%) \\
41(15 \%)\end{array}$ & $<1$ \\
\hline
\end{tabular}




\begin{abstract}
${ }^{\text {a) }}$ Dilute degassed (ca. $10^{-5} \mathrm{M}$ ) solutions. ${ }^{\text {b) }}$ Referenced to $\left[\mathrm{Ru}(\mathrm{bpy})_{3}\right][\mathrm{Cl}]_{2}$ in aerated water conditions $(\Phi=0.04), 1_{\mathrm{ex}}=380 \mathrm{~nm} .{ }^{60 \mathrm{c})}$ Determined under $\mathrm{N}_{2}$ with integrating sphere, $1_{\mathrm{ex}}=380 \mathrm{~nm} .{ }^{\mathrm{d})}$ From TCSPC measurements, all emission data obtained at
\end{abstract} $298 \mathrm{~K}$.

The emission spectra of the powders 1-6 are broad and unstructured with maxima, $\lambda_{\mathrm{PL}}$, ranging from 530-580 $\mathrm{nm}$. In the solid state, complexes 1-3, 5 and $\mathbf{6}$ were moderately emissive ( $\Phi_{\mathrm{PL}}$ up to 35 $\%$ ), while complexes 4 and 7 were again very poorly emissive. Notably 5 was significantly more emissive as a powder $\left(\Phi_{\mathrm{PL}}=18 \%\right)$ than in solution. For powder samples, the $\Phi_{\mathrm{PL}}$ for $\mathbf{1}$ of $14 \%$ and for $\mathbf{2}$ of $11 \%$ match those reported in the literature. ${ }^{18,61}$ The highest $\Phi_{\mathrm{PL}}$ found within the series was for $\mathbf{3}$ at $35 \%$. The emission lifetimes of all moderately emissive powders had a small (2-8 \%) contribution from a fast $(<1 \mu \mathrm{s})$ decay process, with approximately equal contribution from two slower decay processes around $4 \mu \mathrm{s}$ and $12 \mu \mathrm{s}$.

Previously, it had been shown that adding bulky substituents at the $\alpha$-positions to the nitrogen atoms of bipyridyl or phenanthroline ligands would lead to an increase in $\Phi_{\mathrm{PL}}$ by suppressing pseudo Jahn-Teller distortions associated with the as-formed $\mathrm{Cu}^{\text {II }}$ centre upon photoexcitation. ${ }^{18,62}$ Here, we found that selecting $\mathrm{P}^{\wedge} \mathrm{P}$ ligands possessing relatively smaller natural bite angles as well as smaller flexibility ranges also lead to an enhancement of the powder state photoluminescence quantum yield. In solution, the origin of non-radiative decay becomes more complicated. Firstly, the pseudo Jahn-Teller distortion that appears in the excited state of $\mathrm{Cu}(\mathrm{I})$ complexes is an important contributor to the nonradiative decay. ${ }^{63}$ Secondly, the vibrations of flexible moieties within the ligands also contribute to the non-radiative decay.

Although the link between steric hindrance and high photoluminescence quantum yield is qualitatively established with respect to substituents on the dmphen ligand and the phenyl groups of the bisphosphine ligand such as xantphos, little detailed analysis has been directed towards a more quantitative investigation for $\mathrm{Cu}(\mathrm{I})$ complexes. Most previous reports correlate the increase of steric bulk with the P-Cu-P bite angles intuitively without a more robust quantitative analysis. We employed the percent volume buried $\left(\% \mathrm{~V}_{\text {bur }}\right)$ as a metric for the amount of steric hindrance in these complexes with a view to identify a correlation between the steric hindrance about the copper centre and the corresponding $\Phi_{\mathrm{PL}}{ }^{64}$ The $\% \mathrm{~V}_{\text {bur }}$ has previously proven to be a more meaningful parameter than the Tolman cone angles in complexes of N-heterocyclic carbenes and tertiary phosphines, since it can better describe the steric parameters associated with the more flexible ligands such as phosphites. ${ }^{65}$ Complexes 4 and 7 were excluded from this analysis due to their extremely weak (4), or ligand-centred emission (7). While a very poor correlation was found for solution samples $\left(\mathrm{R}^{2}<0.1\right.$, see Figure $\mathbf{S 2 4}$ in supporting 
information), much stronger correlations were found for powder samples (Figure 7). In general, complexes with larger $\% \mathrm{~V}_{\text {bur }}$ tend to have higher $\Phi_{\mathrm{PL}} \mathrm{S}\left(\mathrm{R}^{2}=0.77\right.$ and 0.92 when the sphere radius is set to $3.5 \AA$, the Bondi radii was scaled by 1 and 1.17, respectively). Amongst the five complexes, 3 has the highest $\% \mathrm{~V}_{\text {bur }}$ while its powder $\Phi_{\mathrm{PL}}$ is also the highest (35\%). Complex 2 has the smallest $\% \mathrm{~V}_{\text {bur }}$ and the lowest powder $\Phi_{\mathrm{PL}}(11 \%)$.
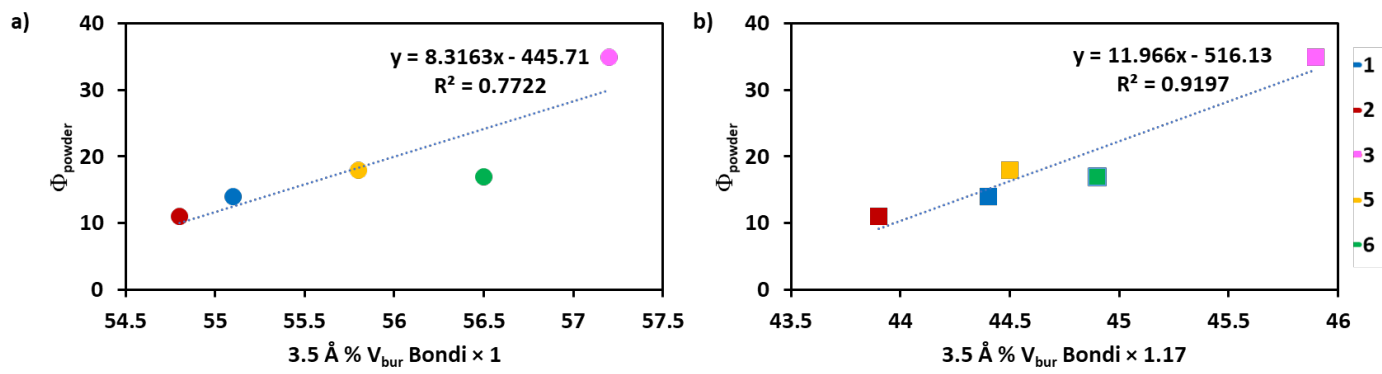

Figure 7. The relationship between $\Phi_{\mathrm{PL}}$ of powder state and percent volume buried $\left(\% \mathrm{~V}_{\text {bur }}\right)$ with either a) Bondi atomic radii or b) Bondi atomic radii scaled by 1.17 .

Turning to spin-coated neat films, the $\Phi_{\mathrm{PL}}$ of complex 1 increased significantly from $12 \%$ in powder to $28 \%$ while for complex 2 there is a modest decrease from $35 \%$ in the powder to $24 \%$ as a neat film. Complexes $\mathbf{3}$ and $\mathbf{5}$ see dramatically lower $\Phi_{\mathrm{PL}}$ while there is no change in $\Phi_{\mathrm{PL}}$ for complex 7. Complexes that previously were very poorly emissive in the powder remained so as neat films. From these results it is apparent that the solid-state packing can have a dramatic effect on the $\Phi_{\mathrm{PL}}$ for structurally similar mononuclear complexes.

\section{Excited State DFT Calculations}

The DFT and TD-DFT calculations described above provide good information on the structure and electronics of these $\mathrm{Cu}(\mathrm{I})$ complexes in the ground state. This is seen through the excellent agreement between calculation and x-ray structures, cyclic voltammetry, and UV-vis spectra. However, these calculations provide very poor information on the excited state of these molecules as they do not capture the pseudo Jahn-Teller distortion experienced by the copper centres in the complexes. To determine the excited state structures of the complexes and elucidate the electronic nature of the emissive state of the complexes we performed DFT and TD-DFT calculations on the first singlet and first triplet excited states, the structures from the DFT calculations are seen in Table 6.

Table 6. Comparison of key structural parameters for calculated ground state, first singlet state and first triplet state structures of complexes 1-7.

\begin{tabular}{cccccccccc}
\hline & \multicolumn{3}{c}{ GS Structure } & \multicolumn{3}{c}{$\mathbf{S}_{1}$ Structure } & \multicolumn{3}{c}{$\mathbf{T}_{1}$ Structure } \\
Complex & $\begin{array}{c}\text { P-Cu-P } \\
\text { bite }\end{array}$ & $\begin{array}{c}\text { Backbone } \\
\text { angle }^{\mathrm{a}}\left({ }^{\circ}\right)\end{array}$ & $\begin{array}{c}\text { Coord. } \\
\text { plane } \\
\text { angle }^{\mathrm{b}}\left({ }^{\circ}\right)\end{array}$ & $\begin{array}{c}\text { P-Cu-P } \\
\text { bite }\end{array}$ & $\begin{array}{c}\text { Backbone } \\
\text { angle }^{\mathrm{a}}\left({ }^{\circ}\right)\end{array}$ & $\begin{array}{c}\text { Coord. } \\
\text { plane } \\
\text { angle }^{\mathrm{b}}\left({ }^{\circ}\right)\end{array}$ & $\begin{array}{c}\text { P-Cu-P } \\
\text { bite }\end{array}$ & $\begin{array}{c}\text { Backbone } \\
\text { angle }^{\mathrm{a}}\left({ }^{\circ}\right)\end{array}$ & $\begin{array}{c}\text { Coord. } \\
\text { plane } \\
\text { angle }^{\mathrm{b}}\left({ }^{\circ}\right)\end{array}$ \\
\hline
\end{tabular}




\begin{tabular}{cccccccccc} 
& $\begin{array}{c}\text { angle } \\
\left({ }^{\circ}\right)\end{array}$ & \multicolumn{9}{c}{$\begin{array}{c}\text { angle } \\
(\mathrm{o})\end{array}$} & & \multicolumn{3}{c}{$\begin{array}{c}\text { angle } \\
(\mathrm{o})\end{array}$} \\
\hline $\mathbf{1}$ & 113.5 & 65.0 & 88.5 & 106.2 & 69.2 & 73.5 & 106.5 & 69.0 & 73.8 \\
$\mathbf{2}$ & 115.1 & 33.1 & 89.8 & 107.5 & 30.8 & 78.6 & 108.4 & 31.5 & 75.6 \\
$\mathbf{3}$ & 112.9 & 38.7 & 85.4 & 103.1 & 40.3 & 71.6 & 103.8 & 40.1 & 71.9 \\
$\mathbf{4}$ & 115.5 & 39.6 & 90.0 & 107.4 & 38.0 & 75.5 & 107.7 & 38.5 & 75.2 \\
$\mathbf{5}$ & 119.2 & 28.5 & 87.5 & 109.4 & 27.4 & 72.8 & 110.2 & 28.4 & 73.3 \\
$\mathbf{6}$ & 115.5 & 35.3 & 87.0 & 105.8 & 35.1 & 72.3 & 106.9 & 35.1 & 72.8 \\
$\mathbf{7}$ & 120.8 & 10.4 & 87.5 & 110.9 & 9.9 & 73.7 & 120.6 & 11.0 & 87.4 \\
\hline
\end{tabular}

a) The angle between the two ether bridged phenyl rings within the $\mathrm{P}^{\wedge} \mathrm{P}$ ligand. ${ }^{\text {b) }}$ The angle between $\mathrm{Cu}\left(\mathrm{P}^{\wedge} \mathrm{P}\right)$ coordination plane and $\mathrm{Cu}\left(\mathrm{N}^{\wedge} \mathrm{N}\right)$ coordination planes.

The calculated structures of complexes 1-7 show the significant change in geometry around the copper centre upon excitation of the molecule, attributed to pseudo Jahn-Teller distortions. Both the $\mathrm{S}_{1}$ and $\mathrm{T}_{1}$ excited states have very similar structures. The major differences seen are the decrease in the P$\mathrm{Cu}-\mathrm{P}$ angle by $8-10^{\circ}$ and the change of $10-15^{\circ}$ in the angle between the $\mathrm{Cu}\left(\mathrm{P}^{\wedge} \mathrm{P}\right)$ and $\mathrm{Cu}\left(\mathrm{N}^{\wedge} \mathrm{N}\right)$ coordination planes.

For TADF, emission occurs from the $\mathrm{S}_{1}$ excited state. Given the observed pseudo Jahn-Teller distortions in the exited state structures of the complexes, the energy of the emissive $\mathrm{S}_{1}$ state will be different to the energy of the $S_{1}$ state in the ground state structure. TD-DFT calculations of the excited state energy levels were performed for the complexes in their excited state geometries and are shown in Table 7. There is a very strong correlation between these $S_{1}$ energy levels with the emission maxima in DCM solution, the exception being complex 7 where the LC excited state seen experimentally is not observed in the calculated $\mathrm{S}_{1}$ energy.

Table 7. Comparison of experimental emission energy and calculated $\mathrm{S}_{1}$ energies at different calculated geometries of complexes 1-7.

\begin{tabular}{cccccccccccc}
\hline & \multicolumn{1}{c}{ DCM Emission } & \multicolumn{1}{c}{ GS Geometry } & \multicolumn{1}{c}{ Calculated S Energy } \\
\multicolumn{1}{c}{$\mathrm{S}_{1}$ Geometry } \\
Complex & $\begin{array}{c}\lambda_{\mathrm{em}} \\
(\mathrm{nm})\end{array}$ & $\begin{array}{c}\mathrm{E} \\
(\mathrm{eV})\end{array}$ & $\begin{array}{c}\lambda_{\mathrm{em}} \\
(\mathrm{nm})\end{array}$ & $\begin{array}{c}\mathrm{E} \\
(\mathrm{eV})\end{array}$ & $\begin{array}{c}\text { Error } \\
(\%)\end{array}$ & $\begin{array}{c}\lambda_{\mathrm{em}} \\
(\mathrm{nm})\end{array}$ & $\begin{array}{c}\mathrm{E} \\
(\mathrm{eV})\end{array}$ & $\begin{array}{c}\text { Error } \\
(\%)\end{array}$ & $\begin{array}{c}\lambda_{\mathrm{em}} \\
(\mathrm{nm})\end{array}$ & $\begin{array}{c}\mathrm{T} \\
(\mathrm{eV})\end{array}$ & $\begin{array}{c}\text { Error } \\
(\%)\end{array}$ \\
\hline $\mathbf{1}$ & 550 & 2.25 & 413 & 3.00 & 33 & 600 & 2.07 & 8 & 603 & 2.06 & 9 \\
$\mathbf{2}$ & 549 & 2.26 & 410 & 3.02 & 34 & 593 & 2.09 & 7 & 595 & 2.08 & 8 \\
$\mathbf{3}$ & 567 & 2.19 & 430 & 2.88 & 32 & 626 & 1.98 & 9 & 627 & 1.98 & 10 \\
$\mathbf{4}$ & 547 & 2.27 & 408 & 3.04 & 34 & 591 & 2.10 & 7 & 595 & 2.08 & 8 \\
$\mathbf{5}$ & 543 & 2.28 & 421 & 2.95 & 29 & 605 & 2.05 & 10 & 605 & 2.05 & 10 \\
$\mathbf{6}$ & 541 & 2.29 & 408 & 3.04 & 33 & 601 & 2.06 & 10 & 602 & 2.06 & 10 \\
$\mathbf{7}$ & 431 & 2.88 & 411 & 3.02 & 5 & 605 & 2.05 & 29 & 453 & 2.74 & 5 \\
\hline
\end{tabular}

Central to the TADF process is a small $\Delta \mathrm{E}_{\mathrm{ST}}$ that facilitates intersystem crossing and reverse intersystem crossing between the $S_{1}$ and $T_{1}$ states. In the literature, calculations of $\Delta E_{S T}$ are routinely performed at the optimised ground state structure. The significant pseudo Jahn-Teller distortion in the 
exited state structures of copper complexes is not captured in these calculations. To address this, we have calculated $\Delta \mathrm{E}_{\mathrm{ST}}$ for the excited state structures of complexes 1-7 (Table 8).

Table 8. Comparison of calculated excited state energy levels at calculated ground state, first singlet state and first triplet state structures of complexes 1-7.

\begin{tabular}{cccccccccc}
\hline & \multicolumn{3}{c}{ GS Structure } & \multicolumn{3}{c}{$\mathbf{S}_{\mathbf{1}}$ Structure } & \multicolumn{3}{c}{$\mathbf{T}_{\mathbf{1}}$ Structure } \\
Complex & $\mathrm{S}_{1}(\mathrm{eV})$ & $\mathrm{T}_{1}(\mathrm{eV})$ & $\Delta \mathrm{E}_{\mathrm{ST}}(\mathrm{eV})$ & $\mathrm{S}_{1}(\mathrm{eV})$ & $\mathrm{T}_{1}(\mathrm{eV})$ & $\Delta \mathrm{E}_{\mathrm{ST}}(\mathrm{eV})$ & $\mathrm{S}_{1}(\mathrm{eV})$ & $\mathrm{T}_{1}(\mathrm{eV})$ & $\Delta \mathrm{E}_{\mathrm{ST}}(\mathrm{eV})$ \\
\hline $\mathbf{1}$ & 3.01 & 2.78 & 0.23 & 2.07 & 1.88 & 0.19 & 2.05 & 1.82 & 0.23 \\
$\mathbf{2}$ & 3.03 & 2.76 & 0.27 & 2.09 & 1.91 & 0.18 & 2.08 & 1.86 & 0.22 \\
$\mathbf{3}$ & 2.88 & 2.68 & 0.21 & 1.98 & 1.78 & 0.20 & 1.98 & 1.72 & 0.26 \\
$\mathbf{4}$ & 3.04 & 2.76 & 0.28 & 2.10 & 1.91 & 0.19 & 2.08 & 1.86 & 0.22 \\
$\mathbf{5}$ & 2.94 & 2.79 & 0.16 & 2.05 & 1.86 & 0.19 & 2.05 & 1.81 & 0.24 \\
$\mathbf{6}$ & 3.04 & 2.79 & 0.25 & 2.06 & 1.86 & 0.20 & 2.06 & 1.81 & 0.25 \\
$\mathbf{7}$ & 3.02 & 2.29 & 0.73 & 2.05 & 1.86 & 0.18 & 2.74 & 1.63 & 1.10 \\
\hline
\end{tabular}

The calculated $\Delta \mathrm{E}_{\mathrm{ST}}$ values for the optimised triplet geometry all lie in the range 0.22 to 0.26 $\mathrm{eV}$, with the exception of 7 which exhibits a LC excited state and has a corresponding much larger $\Delta \mathrm{E}_{\text {ST. }}$ There is very good correlation between the $\Delta \mathrm{E}_{\mathrm{ST}}$ obtained using the ground state geometries and the triplet excited state structures. This suggests that in these complexes, the pseudo Jahn-Teller distortion in the excited state affects both the singlet and triplet energy levels in a similar manner.

\section{Electrochemiluminescence}

The electrochemiluminescence (ECL) behavior of complexes 1-3, 5 and $\mathbf{6}$ was investigated in acetonitrile at a complex concentration of $1 \mathrm{mM}$. The emission spectra in $\mathrm{MeCN}$ are $\sim 15 \mathrm{~nm}$ red-shifted compared to what those in DCM. The reduction potentials in $\mathrm{MeCN}$ are shifted cathodically about 0.2 $\mathrm{V}$ compared to those measured in DCM while the oxidation potentials are shifted cathodically to a greater extent by $0.3 \mathrm{~V}$. hence, the redox gaps are smaller in MeCN than in DCM. Figure S23 shows the ECL spectral response for each complex compared with the photoluminescence response in the same solvent. These spectra reveal that the same excited state is populated regardless of whether electrochemical or optical excitation employed.

There are three modes by which ECL may be elicited, the relative strength of the emission of each complex by each mode is indicated in Table 9. The first mode is annihilation, where the working electrode potential is alternated between values sufficiently negative (reaction 1) and sufficiently positive (reaction 2) to reduce and oxidise the complex, respectively. Note that this solution phase process is effectively the same the same as the solid-state mechanism operational in the LEC. The sequence is summarised in the following reactions, where $\left[\mathrm{Cu}\left(\mathrm{P}^{\wedge} \mathrm{P}\right)(\mathrm{dmphen})\right]^{+}$represents the generalised form of the copper complexes 1-3, 5 and $\mathbf{6}$ : 


$$
\begin{aligned}
& {\left[\mathrm{Cu}\left(\mathrm{P}^{\wedge} \mathrm{P}\right)(\text { dmphen })\right]^{+}+\mathrm{e}^{-} \rightarrow\left[\mathrm{Cu}\left(\mathrm{P}^{\wedge} \mathrm{P}\right)(\text { dmphen })\right]} \\
& {\left[\mathrm{Cu}\left(\mathrm{P}^{\wedge} \mathrm{P}\right)(\text { dmphen })\right]^{+} \rightarrow\left[\mathrm{Cu}\left(\mathrm{P}^{\wedge} \mathrm{P}\right)(\mathrm{dmphen})\right]^{2+}+\mathrm{e}^{-}} \\
& {\left[\mathrm{Cu}\left(\mathrm{P}^{\wedge} \mathrm{P}\right)(\mathrm{dmphen})\right]+\left[\mathrm{Cu}\left(\mathrm{P}^{\wedge} \mathrm{P}\right)(\mathrm{dmphen})\right]^{2+} \rightarrow\left[\mathrm{Cu}\left(\mathrm{P}^{\wedge} \mathrm{P}\right)(\text { dmphen })\right]^{+}+\left[\mathrm{Cu}\left(\mathrm{P}^{\wedge} \mathrm{P}\right)(\text { dmphen })\right]^{+*}} \\
& {\left[\mathrm{Cu}\left(\mathrm{P}^{\wedge} \mathrm{P}\right)(\text { dmphen })\right]^{+*} \rightarrow\left[\mathrm{Cu}\left(\mathrm{P}^{\wedge} \mathrm{P}\right)(\mathrm{dmp})\right]^{+}+\mathrm{h} v}
\end{aligned}
$$

Following reactions (1) and (2), the oxidised and reduced species encounter each other in the diffusion layer adjacent to the electrode, an electron transfer reaction occurs and, if the thermodynamics and kinetics are favourable, one of the products of this reaction will be formed in the excited state (reaction 3). On relaxation of this excited state to the ground state a photon is emitted, which typically will be of the same energy as would be emitted during photoluminescence. Interestingly, of the complexes tested, only $\mathbf{3}$ gave annihilation ECL emission. One of the necessary conditions for ECL is that there be sufficient energy available to populate the excited state from the electron transfer step (reaction 3 above). This can be tested by comparing the values of $\Delta \mathrm{E}^{\circ}$, which correspond to the energy available from reaction between the oxidised and reduced precursors, with the excited state energies of the complexes. Based on the data in Table 9, the available energies range from 2.95 to $3.16 \mathrm{eV}$, while the excited state energies, estimated from the $\lambda_{\mathrm{PL}}$ of the emission spectra, range between 2.1 and $2.2 \mathrm{eV}$. Therefore, the annihilation reaction is energy sufficient in each case and thermodynamics can be readily ruled out as the reason for the absence of ECL from 1, 2, 5 and $\mathbf{6}$. Another important requirement for ECL is that the species involved in the annihilation reaction (reaction 3) be sufficiently stable such that they will encounter each other before degrading into side products. This stability can be established by looking at the chemical reversibility of the cyclic voltammetric responses. Figure $\mathbf{S 2 2}$ shows that only 3 and $\mathbf{5}$ have oxidation processes that are at least quasi-reversible at this voltammetric timescale. On the other hand, all the complexes tested, with the exception of $\mathbf{5}$, have reversible reductions. Therefore, the lack of annihilation ECL from 1, 2, 5 and $\mathbf{6}$ is explained by the fact that $\mathbf{3}$ is the only complex for which both the oxidised and reduced forms are sufficiently electrochemically stable. The ECL efficiency was estimated to be $0.5 \%$ by using $\left[\mathrm{Ru}(\mathrm{bpy})_{3}\right]^{2+}\left(\Phi_{\mathrm{ECL}}=5.0 \%\right)$ annihilation ECL as a comparative standard.

There are two other modes by which ECL may be generated, these are the co-reactant pathways, which involve a sacrificial co-reactant that is either oxidised to produce a powerful reductant or reduced to produce a powerful oxidant. These species react with the oxidised or reduced copper complex, respectively, to produce an excited state on the emitter complex. The oxidative-reduction co-reactant ECL of complexes 1-3, 5 and $\mathbf{6}$ was investigated using tri- $n$-propylamine (TPA) as a co-reactant. There are several reaction pathways that can be followed with TPA, the one relevant to the current study is outlined below. The complex is first oxidised via reaction 2 above,

$$
\mathrm{TPA} \rightarrow \mathrm{TPA}^{\bullet+}+\mathrm{e}^{-}
$$


$\mathrm{TPA}^{\bullet+} \rightarrow \mathrm{TPA}^{\bullet}+\mathrm{H}^{+}$

$\mathrm{TPA}^{\bullet}+\left[\mathrm{Cu}\left(\mathrm{P}^{\wedge} \mathrm{P}\right)(\mathrm{dmphen})\right]^{2+} \rightarrow\left[\mathrm{Cu}\left(\mathrm{P}^{\wedge} \mathrm{P}\right)(\mathrm{dmphen})\right]^{+*}+$ product

Followed by emission via reaction 4 .

Not surprisingly, given the lack of reversible oxidative electrochemistry, most complexes showed only weak or medium intensity co-reactant ECL with TPA, with only complex $\mathbf{3}$ giving strong ECL. Based on a comparison of the ECL intensities under similar conditions, we estimated the ECL efficiency to be about $10 \%$ that of the well-known ECL benchmark, $\left[\operatorname{Ru}(\mathrm{bpy})_{3}\right]^{2+}$.

Finally, the reductive-oxidation co-reactant ECL of the complexes was tested in the presence of ammonium persulfate (APS). Again, there are several possible reaction routes and only the relevant one is outlined here. The complex is first reduced via reaction 1 above, followed by emission via reaction 4.

$$
\begin{aligned}
& \mathrm{S}_{2} \mathrm{O}_{8}{ }^{2-}+\mathrm{e}^{-} \rightarrow \mathrm{S}_{2} \mathrm{O}_{8}{ }^{\bullet 3-} \\
& \mathrm{S}_{2} \mathrm{O}_{8}{ }^{\bullet-} \rightarrow \mathrm{SO}_{4}{ }^{2-}+\mathrm{SO}_{4}{ }^{\bullet-} \\
& {\left[\mathrm{Cu}\left(\mathrm{P}^{\wedge} \mathrm{P}\right)(\text { dmphen })\right]+\mathrm{SO}_{4}{ }^{\bullet-} \rightarrow\left[\mathrm{Cu}\left(\mathrm{P}^{\wedge} \mathrm{P}\right)(\text { dmphen })\right]^{+*}+\mathrm{SO}_{4}{ }^{2-}}
\end{aligned}
$$

Persulfate co-reactant ECL is not known for producing high intensity emission, nonetheless, complexes $\mathbf{1}$ and $\mathbf{6}$ gave moderately intense emission via this route with $\mathbf{2}$ and $\mathbf{3}$ giving weak ECL.

\begin{tabular}{|c|c|c|c|c|c|c|c|c|}
\hline \multirow[b]{2}{*}{ Complex } & \multirow{2}{*}{$\begin{array}{c}\mathbf{E}_{\mathbf{o x}}^{\mathbf{o}} \\
{[\mathrm{V} \text { vs }} \\
\mathrm{SCE}]^{\mathrm{a}}\end{array}$} & \multirow{2}{*}{$\begin{array}{l}\mathbf{E}_{\text {red }} \\
{[\mathrm{V} \text { vs }} \\
\mathrm{SCE}]\end{array}$} & \multirow{2}{*}{$\begin{array}{l}\Delta \mathbf{E}^{\mathbf{o}} \\
{[\mathrm{V}]}\end{array}$} & \multirow{2}{*}{$\begin{array}{l}\lambda_{\mathbf{P L}} \\
\quad[\mathrm{nm}]^{\mathrm{b}}\end{array}$} & \multirow{2}{*}{$\begin{array}{r}\lambda_{\mathrm{ECL}} \\
{[\mathrm{nm}]^{\mathrm{c}}}\end{array}$} & \multicolumn{3}{|c|}{ ECL Intensity ${ }^{\mathrm{d}}$} \\
\hline & & & & & & $\begin{array}{l}\text { Annihil } \\
\text { ation }^{\mathrm{e}}\end{array}$ & $\begin{array}{l}\text { TPA co- } \\
\text { reactant }^{\mathrm{f}}\end{array}$ & $\begin{array}{l}\text { APS co- } \\
\text { reactant }\end{array}$ \\
\hline 1 & $(0.98)$ & -2.14 & 3.09 & 562 & 577 & $\mathrm{x}$ & $\mathrm{w}$ & $\mathrm{m}$ \\
\hline 2 & $(1.02)$ & -2.09 & 3.08 & 563 & 575 & $\mathrm{x}$ & $\mathrm{m}$ & $\mathrm{w}$ \\
\hline 3 & 0.85 & -2.13 & 2.95 & 576 & 588 & $\mathrm{~s}$ & $\mathrm{~s}$ & $\mathrm{w}$ \\
\hline 5 & 0.59 & $(-2.19)$ & 2.78 & - & - & $\mathrm{x}$ & $\mathrm{x}$ & $\mathrm{x}$ \\
\hline 6 & $(1.07)$ & -2.12 & 3.16 & 560 & 566 & $\mathrm{x}$ & $\mathrm{m}$ & $\mathrm{m}$ \\
\hline
\end{tabular}

Table 9. Electrochemical, photophysical and electrochemiluminescence (ECL) data for complexes $\mathbf{1}$,

$\mathbf{2}, \mathbf{3}, \mathbf{5}$ and $\mathbf{6}$ in acetonitrile.

a) Cyclic voltammograms were recorded at $50 \mathrm{mV}^{-1}$ in deaerated acetonitrile containing $0.1 \mathrm{M}$ $\left({ }^{n} \mathrm{Bu}_{4} \mathrm{~N}\right) \mathrm{PF}_{6}, \mathrm{E}^{\mathrm{o}}$ is defined as the mid-point between the oxidation and reduction peak, values in parentheses represent peak potentials for chemically irreversible processes. ${ }^{\text {b) }}$ Photoluminescence 
spectra were measured in deaerated acetonitrile at $298 \mathrm{~K}$ at a concentration of $10 \mu \mathrm{M}$ using an excitation wavelength of $380 \mathrm{~nm}$. ${ }^{\text {c) }}$ All ECL spectra were measured in deaerated acetonitrile containing $0.1 \mathrm{M}$ $\left({ }^{n} \mathrm{Bu}_{4} \mathrm{~N}\right) \mathrm{PF}_{6}$ at a complex concentration of $1 \mathrm{mM}$. ${ }^{\text {d) }}$ Deaerated acetonitrile containing $0.1 \mathrm{M}$ $\left({ }^{n} \mathrm{Bu}_{4} \mathrm{~N}\right) \mathrm{PF}_{6}$ at a complex concentration of $1 \mathrm{mM} . \mathrm{x}=$ no ECL, $\mathrm{w}=$ weak, $\mathrm{m}=$ medium, $\mathrm{s}=$ strong. ${ }^{\mathrm{e})}$ Annihilation ECL was elicited by stepping sequentially $50 \mathrm{mV}$ past the first oxidation peak then the first reduction peak. ${ }^{\text {f) }}$ TPA co-reactant ECL was elicited by stepping $50 \mathrm{mV}$ past the first oxidation peak in the presence of $5 \mathrm{mM}$ TPA. ${ }^{\mathrm{g})}$ APS co-reactant ECL was elicited by stepping $50 \mathrm{mV}$ past the first reduction peak in the presence of $5 \mathrm{mM}$ APS.

Similar to what we found for solid-state photoluminescence, complex 3 exhibited stronger annihilation ECL and TPA co-reactant ECL while the other four complexes showed only moderate or weak ECL emission. None of the complexes exhibited strong ECL with APS co-reactant; however, complexes 1 and $\mathbf{6}$ did show stronger ECL compared to complex $\mathbf{3}$, which only showed weak ECL with APS co-reactant. No significant correlation was observed between ECL intensities and percent volume buried (Figure S25). To the best of our knowledge, this is the first ECL study involving heteroleptic copper (I) complexes. Despite the potential advantages of low cost, ease of synthesis and ease of purification, reports of electrochemiluminescent copper complexes are exceedingly rare; and usually the emission is found to be very weak. An example, $\left[\mathrm{Cu}(\mathrm{dmphen})_{2}\right]^{+}$was reported by McCall in $2001^{66}$ to give weak co-reactant ECL (co-reactant used: tri- $n$-propylamine), which was slightly enhanced in the presence of surfactant. The scarcity of copper-based electrochemiluminophores is perhaps not surprising given the photophysical and electrochemical criteria that need to be satisfied for efficient ECL. In particular, the oxidative instability of such compounds appears to be the main confounding factor. In this context, the ECL exhibited by complex $\mathbf{3}$ in the present study (vide infra), although somewhat lower than that of the ruthenium-based standard, is exceptional and suggests that complexes of this class should be pursued as a potentially fruitful avenue for the discovery of new electrochemiluminophores.

\section{Electroluminescence}

The electroluminescence (EL) of the series of complexes was initially tested in light-emitting electrochemical cells (LECs), in view of the ionic character of the compounds. Complexes 4 and 7 were not implemented in devices because of their low $\Phi_{\mathrm{PL}}$ in the neat thin films. Planar LECs (structure in Figure 8a) were prepared on pre-patterned indium tin oxide (ITO) glass substrates, coated with a thin layer of poly(3,4-ethylenedioxythiophene) polystyrene sulfonate (PEDOT:PSS, $40 \mathrm{~nm}$ ) to smooth the ITO surface and increase its work function. The emissive layer (EML) consisted of a mixture of each complex and $\mathrm{LiBF}_{4}$ (9:1 molar ratio), which is added to increase the ionic conductivity within the film. 
The EML was spin-coated from $20 \mathrm{mg} / \mathrm{mL}$ acetonitrile solutions of the complex with the ionic additive. Devices were finished with the vacuum-deposition of an aluminum cathode. Characterization was carried out in a nitrogen-filled glovebox without encapsulation, and LECs were driven with pulsed current (100 A m $\mathrm{A}^{-2}$ average current density, $1 \mathrm{kHz}, 50 \%$ duty cycle) while monitoring the electroluminescence intensity. The optoelectronic characterization of the LECs is reported in Figure 8 , while the main performance parameters are summarized in Table 10. Note that we also measured the $\Phi_{\mathrm{PL}}$ of thin films with the same composition as the EML of LECs (in the presence of $\mathrm{LiBF}_{4}$ ), and found a large increase in luminescence efficiency (Table 10), which might be ascribed to a dilution effect of the $\mathrm{LiBF}_{4}$. We detected electroluminescence within a few tens of second after biasing the devices, with the exception of complex $\mathbf{3}$, which showed instantaneous turn-on, and of complex $\mathbf{5}$, which displayed only negligible luminescence even after hours of operation. The latter observation correlates with the low $\Phi_{\mathrm{PL}}$ in the solid state. Most likely, under current injection, complex 5 undergoes some degree of chemical degradation, as suggested from its EL spectrum (Figure 8c), possibly a consequence of its low oxidation potential (Table 3). The rest of the complexes show EL spectra in LECs with emission maxima at about $575 \mathrm{~nm}$, with complex 3 showing a slightly red-shifted emission peaking at $582 \mathrm{~nm}$. These values are systematically red-shifted with respect to the PL obtained from films with the same composition as the EML (with $\mathrm{LiBF}_{4}$ ). See Table $\mathbf{S 3}$ for a detailed overview of the spectral features for all complexes.

a)

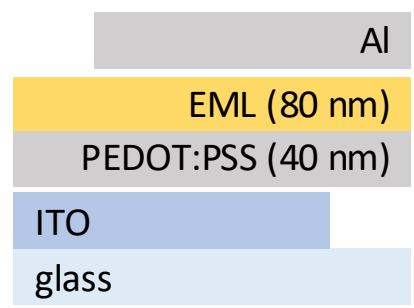

c)

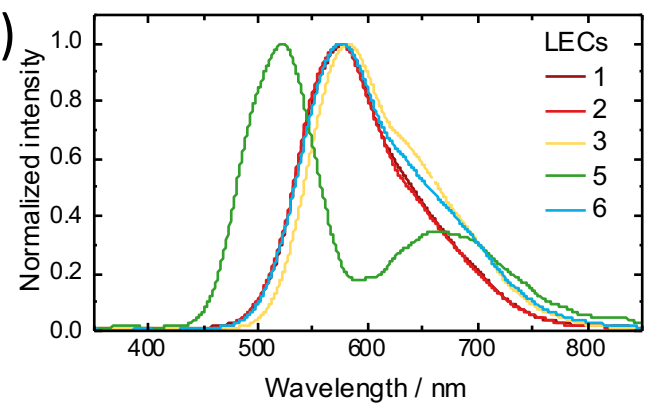

b)

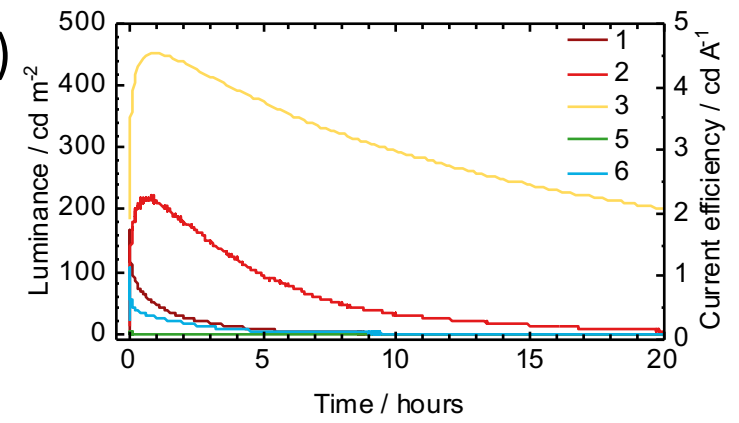

d)

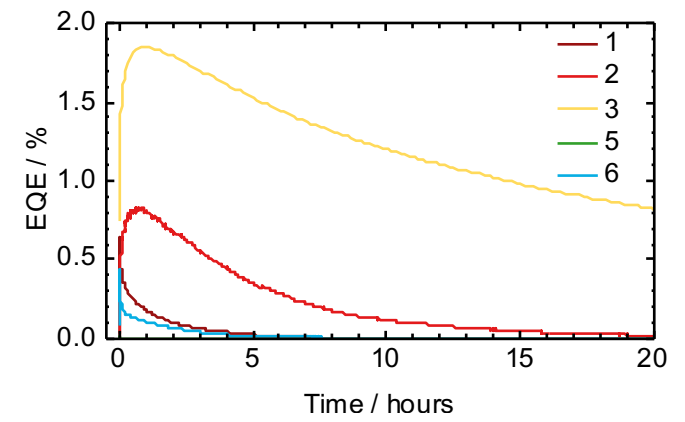

Figure 8. (a) Schematic of the device layout used for LECs. (b) Luminance (left) and corresponding current efficiency (CE, right) vs. time for devices driven at $100 \mathrm{~A} \mathrm{~m}^{-2}$. (c) Electroluminescence spectra and (d) evolution of the external quantum efficiency (EQE) over time for the same device series. 
All devices show the typical evolution of the electroluminescence vs. time, with an early maximum followed by a decay whose slope varies with the nature of the complex, resulting in lifetimes $\left(\mathrm{t}_{1 / 2}\right.$, time to decay to half $\operatorname{Lum}_{\max }$ ) of tens of hours at best for complex 3 . The maximum detected luminance $\left(\right.$ Lum $\left._{\max }\right)$ varies from approximately $100 \mathrm{~cd} \mathrm{~m}^{-2}$ for complex $\mathbf{6}$, to $450 \mathrm{~cd} \mathrm{~m}^{-2}$ for complex $\mathbf{3}$, corresponding to maximum current efficiencies $\left(\mathrm{CE}_{\max }\right)$ of 1.1 and $4.5 \mathrm{~cd} \mathrm{~A}^{-1}$, respectively. As detailed in Table 9, the maximum external quantum efficiency $\left(\mathrm{EQE}_{\max }\right)$ for the LECs varies from about 0.5 to $2 \%$, indicating the presence of severe non-radiative recombination losses. In order to quantify them, we calculate the ratio of $\mathrm{EQE}_{\max }$ to the maximum theoretical efficiency for each complex (EQE $\mathrm{E}_{\text {theo }}$ ), which we approximate to the product of the $\Phi_{\mathrm{PL}}$ and the light outcoupling efficiency $(\approx 0.2)$, considering carrier balance and exciton generation efficiency as unity. Such quantum yield ratio (QYR) permits a quantification of the losses in spite of the different $\Phi_{\mathrm{PL}}$ for each complex. 
Table 10. Electroluminescent performance of LECs.

\begin{tabular}{|c|c|c|c|c|c|c|c|c|c|c|c|c|}
\hline \multirow{2}{*}{ Name } & \multirow{2}{*}{$\begin{array}{c}\text { PLQY } \\
\%\end{array}$} & \multicolumn{6}{|c|}{ LECs } & \multicolumn{5}{|c|}{ OLEDs } \\
\hline & & $\begin{array}{c}\mathbf{t}_{\mathrm{on}} / \\
\mathrm{s}\end{array}$ & $\begin{array}{l}\operatorname{Lum}_{\max } \\
\text { cd m}^{-2}\end{array}$ & $\begin{array}{c}\mathbf{t}_{1 / 2} / \\
h\end{array}$ & $\begin{array}{l}\mathrm{CE}_{\max } / \\
{\operatorname{cd~} \mathrm{A}^{-1}}^{-1}\end{array}$ & $\begin{array}{c}\mathrm{EQE}_{\max } / \\
\%\end{array}$ & QYR & $\begin{array}{l}\text { Lum }_{\text {max }} \\
\text { cd m }^{-2}\end{array}$ & 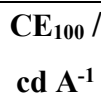 & $\begin{array}{r}\mathrm{CE}_{\max } / \\
{\operatorname{cd~} \mathrm{A}^{-1}}^{-1}\end{array}$ & $\begin{array}{c}\mathrm{EQE}_{\max } / \\
\%\end{array}$ & QYR \\
\hline 1 & 48 & 26 & 169 & 0.2 & 1.7 & 0.65 & 0.07 & 1860 & 4.9 & 11.1 & 3.6 & 0.38 \\
\hline 2 & 38 & 44 & 223 & 4.3 & 2.2 & 0.84 & 0.11 & 101 & 0.4 & 0.7 & 0.2 & 0.03 \\
\hline 3 & 54 & 0 & 452 & 16.5 & 4.5 & 1.85 & 0.17 & 937 & 7.4 & 13.9 & 4.4 & 0.41 \\
\hline 5 & 9 & N/A & 2 & N/A & N/A & N/A & N/A & 243 & 0.6 & 0.7 & 0.2 & 0.11 \\
\hline 6 & 11 & 18 & 108 & 0.1 & 1.1 & 0.45 & 0.20 & 575 & 2.8 & 7.1 & 2.5 & $\approx 1$ \\
\hline
\end{tabular}

The QYR shows that non radiative losses are more severe for devices with complexes $\mathbf{1}$ and $\mathbf{2}$ (EQE $E_{\max }$ is at approximately $10 \%$ of the theoretical maximum), while they are somewhat attenuated for complexes 3 and $\mathbf{6}$ (about 20\%). While LECs based on complex $\mathbf{6}$ are limited in efficiency by the $\Phi_{\mathrm{PL}}$ of the compound, those prepared for the LEC with complex 3 show a combination of intense electroluminescence and promising stability, with a lifetime of 16.5 hours. The $\mathrm{EQE}_{\max }$ of complex 3 $(1.85 \%)$ is lower than that reported for $[\mathrm{Cu}(\mathrm{DPEPhos})(\mathrm{dnbp})]^{+}\left(\mathrm{EQE}_{\max }=16 \%\right.$, the structure can be found in Figure S26), the LEC employing complex 3 is much more stable $\left(\mathrm{t}_{1 / 2}=1.25\right.$ versus $16.5 \mathrm{~h}$ for $[\mathrm{Cu}(\mathrm{DPEPhos})(\mathrm{dnbp})]^{+}$and complex 3, respectively). ${ }^{67}$ With these performance metrics, LECs based on complex $\mathbf{3}$ are among the highest performing LECs demonstrated with similar $\mathrm{Cu}(\mathrm{I})$ complexes (e.g., $\mathrm{EQE}_{\max }=1.8 \%, 1.7 \%$ and $1.1 \%$ for $[\mathrm{Cu}(\mathrm{DPEPhos})(2-\mathrm{Etphen})]^{+},\left[\mathrm{Cu}(\mathrm{xantphos})\left(4,5,6-\mathrm{Me}_{3} \mathrm{bpy}\right)\right]^{+}$and $[\mathrm{Cu}(\mathrm{xantphos})(2-E t p h e n)]^{+}$, respectively, the structures of these can be seen in Figure S26). ${ }^{22,26}$

In LECs, a single compound (the $\mathrm{Cu}(\mathrm{I})$ complex in this case) has to sustain the processes of charge injection, transport, and recombination, unavoidably limiting the upper efficiency of this type of EL device. In organic light-emitting diodes (OLEDs), each process is carried out by different materials located in different layers of the device, which explains why state-of-the-art OLEDs can compete with other solid-state lighting technologies in terms of both efficiency and stability. ${ }^{68}$ In order to study the EL properties of the series of complexes decoupling their charge injection/transport ability, we have prepared solution-processed multilayer OLEDs (structure in Figure 9a) using the complexes as emitters in a host-guest EML. Briefly, OLEDs were prepared on patterned glass/ITO substrates coated with PEDOT:PSS. A thin layer of the hole-transporting material (HTM) N4,N4'-di(naphthalen-1-yl)-N4,N4'bis(4-vinylphenyl)biphenyl-4,4'-diamine (VNPB) was spin-coated from $5 \mathrm{mg} \mathrm{mL}^{-1}$ solutions in toluene and annealed at $180^{\circ} \mathrm{C}$ for 30 minutes. The thermal treatment triggers the cross-linking of the HTM, allowing subsequent solution-processing of the EML on top of the HTM. The EML consisted of a blend of 4,4',4-tris(carbazol-9-yl)triphenylamine (TCTA) and 1,3-bis[2-(4-tert-butylphenyl)-1,3,4-oxadiazo5-yl]benzene (OXD-7), with 5 wt.\% of the complex. The mixture was spin-coated from chlorobenzene solutions ( $5 \mathrm{mg} \mathrm{mL}^{-1}$ TCTA, $5 \mathrm{mg} \mathrm{mL}^{-1}$ OXD-7, $5 \mathrm{wt} . \% \mathrm{Cu}(\mathrm{I})$ complex) and annealed at $100^{\circ} \mathrm{C}$ for 15 minutes, resulting in $30 \mathrm{~nm}$-thick films. Devices were finished with the deposition of a $40 \mathrm{~nm}$ thick film 
of 1,3-bis[3,5-di(pyridin-3-yl)phenyl]benzene (BmPyPhB), used as electron transport material (ETM) and a $\mathrm{Ba}(5 \mathrm{~nm}) / \mathrm{Ag}(100 \mathrm{~nm})$ bilayer cathode. The optoelectronic characterization is reported in Figure 9, while the main performance parameters are summarized in Table $\mathbf{1 0 .}$

a)

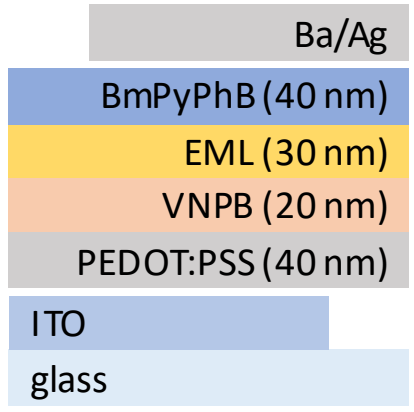

c)

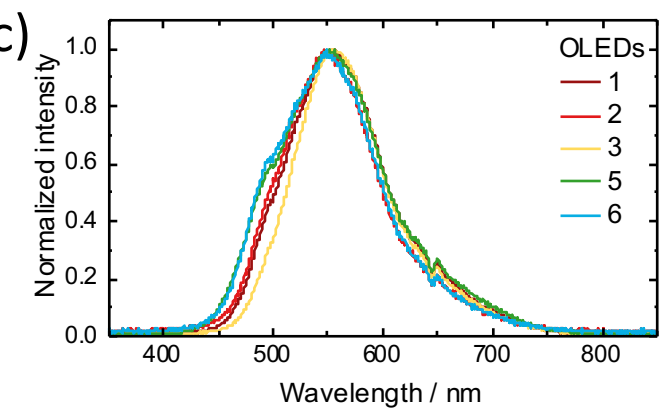

b)

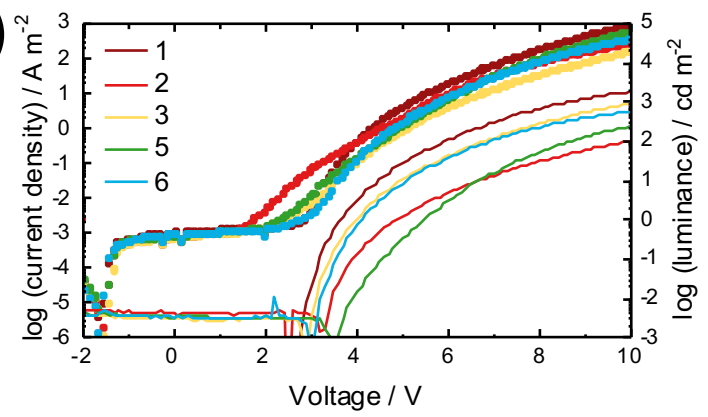

d)

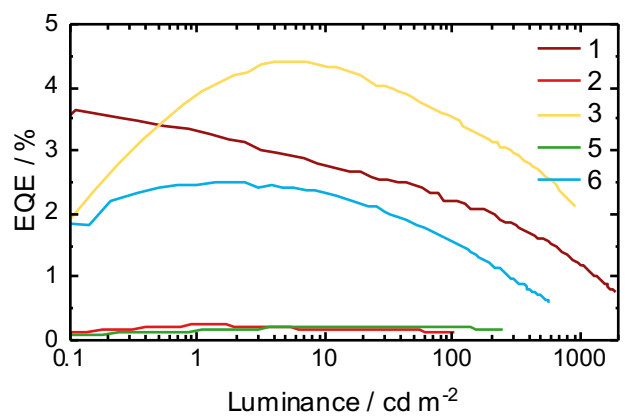

Figure 9. a) The standard structure of OLED devices; b) The current density and luminance vs. voltage (J-V-L) curves; c) The normalised emission spectra of OLED devices; d) The external quantum efficiency (EQE) of OLED devices.

The current density and luminance vs. voltage (J-V-L) curves (Figure 9b) were collected in the -2 to 10 $\mathrm{V}$ range. All devices show a low current density $\left(<10^{-3} \mathrm{~A} \mathrm{~m}^{-2}\right)$ in the low voltage regime, a sign of a high-quality diode. Current injection started at about $2 \mathrm{~V}$, with a steep rise reaching current densities in between $10^{2}$ and $10^{3} \mathrm{~A} \mathrm{~m}^{-2}$ at $10 \mathrm{~V}$. The corresponding turn-on voltage (voltage where EL is detected from the photodiode sensor) was around $3 \mathrm{~V}$. The maximum luminance registered at the same bias voltage varied substantially depending on the copper complex used as the emitter. Electroluminescence could be detected in OLEDs made using complex 5 (in contrast to the LECs), with a Lum max $_{2} 243 \mathrm{~cd}$ $\mathrm{m}^{-2}$, corresponding to moderate $\mathrm{CE}_{\max }$ and $\mathrm{EQE}_{\max }$ of $0.7 \mathrm{~cd} \mathrm{~A}^{-1}$ and $0.2 \%$, respectively. In spite of the good $\Phi_{\mathrm{PL}}$, the OLED with complex 2 showed rather weak EL $\left(\operatorname{Lum}_{\max }=100 \mathrm{~cd} \mathrm{~m}^{-2}\right)$, with $\mathrm{CE}_{\max }$ and $\mathrm{EQE}_{\max }$ of only $0.7 \mathrm{~cd} \mathrm{~A}^{-1}$ and $0.2 \%$, lower even than those measured in LECs. Bright devices were obtained with complexes 1, 3 and 6, displaying Lum $_{\max }$ of 1860, 937 and $575 \mathrm{~cd} \mathrm{~m}^{-2}$ that corresponds to $\mathrm{CE}_{\max }$ of $11.1,13.9$ and $7.1 \mathrm{~cd} \mathrm{~A}^{-1}$, respectively. The $\mathrm{EQE}_{\max }$ of the same OLEDs based on complexes 1, 3 and $\mathbf{6}$ was hence improved compared to the analogous LECs, up to 3.6, 4.4 and 2.5\%, respectively. Looking at the QYR calculated for the OLEDs (Table 10), the devices employing complexes $\mathbf{1}$ and $\mathbf{3}$ reached approximately $40 \%$ of the theoretical maximum efficiency, while the device with complex 6 was found to have an EQE close to the theoretical limit, considering the moderate $\Phi_{\mathrm{PL}}$ of $11 \%$. Indeed, 
this demonstrates that $\mathrm{Cu}(\mathrm{I})$ complexes do suffer from strong EL quenching in LECs but can be used in efficient electroluminescent devices when they are not responsible for the charge injection and transport processes in the EL devices.

The relationships between EL device performances and percent volume buried $\left(\% \mathrm{~V}_{\text {bur }}\right)$ were studied for the 5 complexes. For both OLEDs and LECs, a moderate trend is revealed that seems to suggest that complexes with large $\% \mathrm{~V}_{\text {bur }}$ also show higher $\mathrm{EQE}_{\max }$, as this latter factor is directly proportional to $\Phi_{\mathrm{PL}}$.
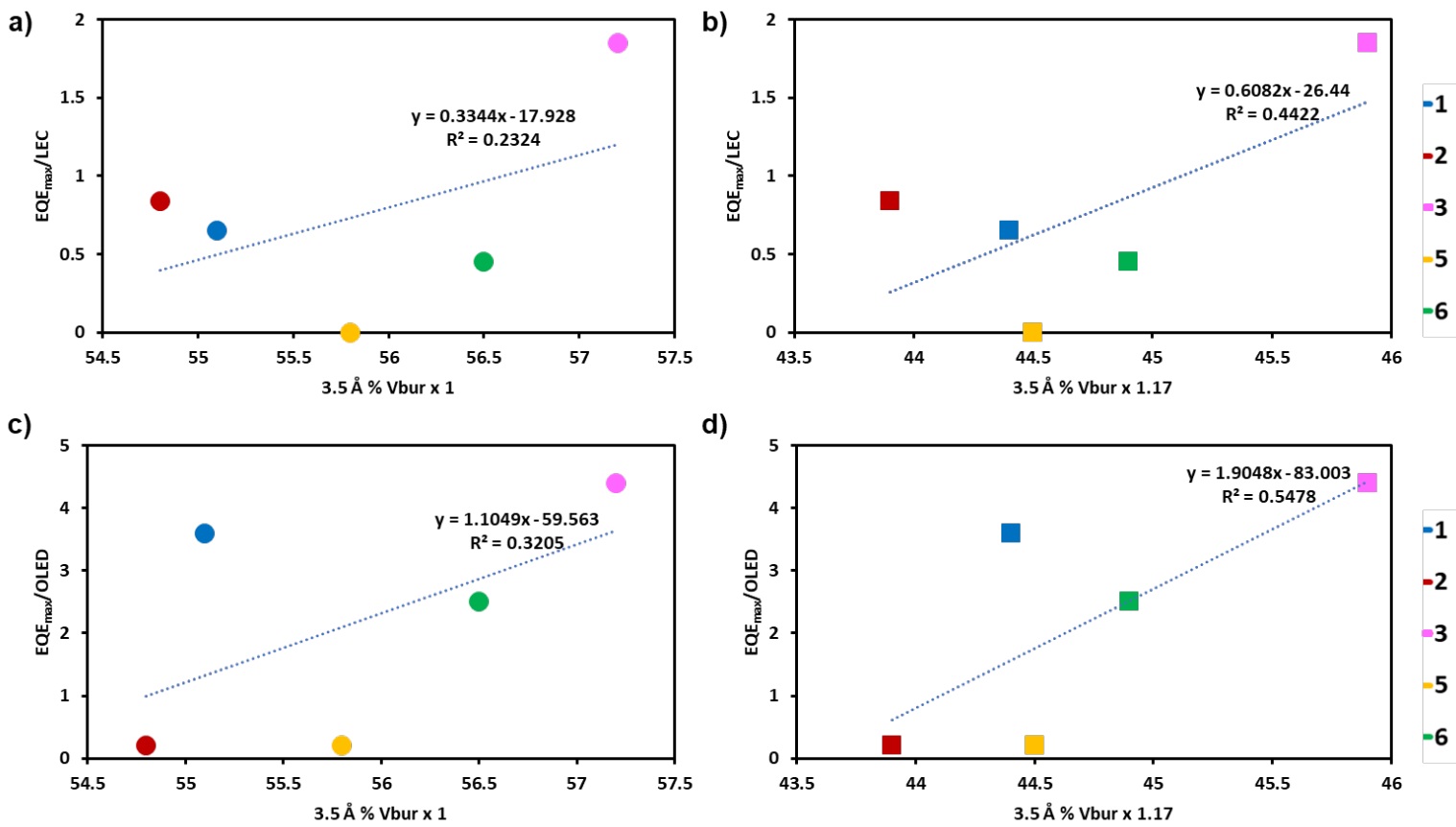

Figure 10. Correlations between $\operatorname{LEC}(\mathrm{a}, \mathrm{b}) / \operatorname{OLED}(\mathrm{c}, \mathrm{d}) \mathrm{EQE}_{\max }$ and percent volume buried $\left(\% \mathrm{~V}_{\mathrm{bur}}\right)$.

\section{Conclusions}

Herein, we studied the photophysics, electrochemistry and electroluminescence of a family of seven heteroleptic $\mathrm{Cu}(\mathrm{I})$ complexes. In contrast to previous studies that focused more on structural modification of the $\mathrm{N}^{\wedge} \mathrm{N}$ ligands, ${ }^{22,27}$ our study focuses on the use of a range of structurally distinct $\mathrm{P}^{\wedge} \mathrm{P}$ ligands within the $\mathrm{Cu}(\mathrm{I})$ complexes. The use of homoxantphos, isopropxantphos, nixantphos, thixantphos and benzoxantphos within $\mathrm{Cu}(\mathrm{I})$ complexed is unprecedented in electroluminescent studies. Comparison of the structures of the complexes with the solid-state photophysics revealed that complexes with higher $\% \mathrm{~V}_{\text {bur }}$ generally have higher $\Phi_{\mathrm{PL}}$. Further, studies on the performance of LECs and OLEDs demonstrated similar correlations between $\% \mathrm{~V}_{\text {bur }}$ and $\mathrm{EQE}_{\max }$. Amongst all seven complexes, complex 3 , which has the highest $\% \mathrm{~V}_{\text {bur, }}$, showed the highest solid-state $\Phi_{\mathrm{PL}}(54 \%)$ as well as the highest $\mathrm{EQE}_{\max }$ for the LEC (1.85\%) and OLED (4.4\%) devices. Complex 3 also showed an improved ECL performance compared to the others in the family. This was explained by the improved 
stability of both oxidised and reduced forms, which was apparent in its voltammetric profile. To the best of our knowledge, this is the first ECL study involving heteroleptic copper (I) complexes. Compared to the benchmark of $\mathrm{Cu}(\mathrm{I})$-based LECs, [Cu(dnbp)(DPEPhos) $]^{+}$, complex 3 showed much longer device lifetime $\left(\mathrm{t}_{1 / 2}=1.25 \mathrm{~h}\right.$ and $>16.5 \mathrm{~h}$ for $[\mathrm{Cu}(\mathrm{dnbp})(\mathrm{DPEPhos})]^{+}$and complex $\mathbf{3}$, respectively).

\section{Acknowledgements}

C. L. thanks the Prof. \& Mrs Purdie Bequests Scholarship and AstraZeneca for a PhD Studentship. The St Andrews researchers thank the Engineering and Physical Sciences Research Council (EP/M02105X/1 and EP/R035164/1) for financial support. A.K.P. acknowledges the Leverhulme Trust and the University of St Andrews for an Early Career Fellowship (ECF-2017-326). H. J. B. and M. S. acknowledge funding from the Spanish Ministry of Science, Innovation and Universities (MAT2017-88821-R and RYC-2016-21316, respectively). C.F.H. acknowledges the support of the Australian Research Council (ARC) Discovery grant scheme (DP200102947).

\section{Supporting Information}

Supporting information document is available online containing; detailed experimental details and characterisation data for each complex, NMR Spectra, UV-vis spectra, emission spectra, details of X-ray crystallography. CCDC numbers (2061118-2061124) contain the supplementary crystallographic data for this article. These, details of device fabrication, details of ECL experiments, details of DFT calculations.

.xyz file of optimised atomic coordinates for all structures modelled by DFT are available.

\section{References}

1 L. H. Xie, C. R. Yin, W. Y. Lai, Q. L. Fan and W. Huang, Prog. Polym. Sci., 2012, 37, $1192-$ 1264.

2 M. A. McCarthy, B. Liu, E. P. Donoghue, I. Kravchenko, D. Y. Kim, F. So and A. G. Rinzler, Science (80-. )., 2011, 332, 570-573.

3 S. Keller, A. Pertegás, G. Longo, L. Martínez, J. Cerdá, J. M. Junquera-Hernández, A. Prescimone, E. C. Constable, C. E. Housecroft, E. Ortí and H. J. Bolink, J. Mater. Chem. C, 2016, 4, 3857-3871.

4 J. Wu, F. Li, Q. Zeng, C. Nie, P. C. Ooi, T. Guo, G. Shan and Z. Su, Org. Electron., 2016, 28, 314-318.

5 H. J. Son, L. Lu, W. Chen, T. Xu, T. Zheng, B. Carsten, J. Strzalka, S. B. Darling, L. X. Chen and L. Yu, Adv. Mater., 2013, 25, 838-843.

6 J. You, L. Dou, K. Yoshimura, T. Kato, K. Ohya, T. Moriarty, K. Emery, C. C. Chen, J. Gao, G. Li and Y. Yang, Nat. Commun., 2013, 4, 1446. 

2014, 26, 2022-2027.

8 M. Vendrell, D. Zhai, J. C. Er and Y. T. Chang, Chem. Rev., 2012, 112, 4391-4420.

$9 \quad$ M. Y. Wong and E. Zysman-Colman, Adv. Mater., 2017, 29, 1605444.

10 Z. Yang, Z. Mao, Z. Xie, Y. Zhang, S. Liu, J. Zhao, J. Xu, Z. Chi and M. P. Aldred, Chem. Soc. Rev., 2017, 46, 915-1016.

11 O. S. Wenger, J. Am. Chem. Soc., 2018, 140, 13522-13533.

12 H. Yersin, A. F. Rausch, R. Czerwieniec, T. Hofbeck and T. Fischer, Coord. Chem. Rev., 2011, 255, 2622-2652.

13 R. Czerwieniec, M. J. Leitl, H. H. H. Homeier and H. Yersin, Coord. Chem. Rev., 2016, 325, $2-$ 28.

14 H. Uoyama, K. Goushi, K. Shizu, H. Nomura and C. Adachi, Nature, 2012, 492, 234-238.

15 J. R. Kirchhoff, R. E. Gamache, M. W. Blaskie, A. A. D. Paggio, R. K. Lengel and D. R. Mcmillin, Inorg. Chem., 1983, 22, 2380-2384.

16 Q. Zhang, Q. Zhou, Y. Cheng, L. Wang, D. Ma, X. Jing and F. Wang, Adv. Mater., 2004, 16, 432-436.

17 C. S. Smith, C. W. Branham, B. J. Marquardt and K. R. Mann, J. Am. Chem. Soc., 2010, 132, 14079-14085.

18 D. G. Cuttell, S. M. Kuang, P. E. Fanwick, D. R. McMillin and R. A. Walton, J. Am. Chem. Soc., 2002, 124, 6-7.

19 A. C. Hernandez-Perez and S. K. Collins, Acc. Chem. Res., 2016, 49, 1557-1565.

20 O. Reiser, Acc. Chem. Res., 2016, 49, 1990-1996.

21 B. M. Hockin, C. Li, N. Robertson and E. Zysman-Colman, Catal. Sci. Technol., 2019, 9, 889915.

22 S. Keller, A. Prescimone, M. G. La Placa, J. M. Junquera-Hernández, H. J. Bolink, E. C. Constable, M. Sessolo, E. Ortí and C. E. Housecroft, RSC Adv., 2020, 10, 22631-22644.

23 M. Alkan-Zambada, S. Keller, L. Martínez-Sarti, A. Prescimone, J. M. Junquera-Hernández, E. C. Constable, H. J. Bolink, M. Sessolo, E. Ortí and C. E. Housecroft, J. Mater. Chem. C, 2018, 6, 8460-8471.

24 S. Keller, A. Prescimone, H. Bolink, M. Sessolo, G. Longo, L. Martínez-Sarti, J. M. JunqueraHernández, E. C. Constable, E. Ortí and C. E. Housecroft, Dalt. Trans., 2018, 47, 14263-14276.

25 M. D. Weber, M. Viciano-Chumillas, D. Armentano, J. Cano and R. D. Costa, Dalt. Trans., 2017, 46, 6312-6323.

26 N. Arnosti, F. Brunner, I. Susic, S. Keller, J. M. Junquera-Hernández, A. Prescimone, H. J. Bolink, M. Sessolo, E. Ortí, C. E. Housecroft and E. C. Constable, Adv. Opt. Mater., 2020, 8, 1901689.

27 M. Alkan-Zambada, E. C. Constable and C. E. Housecroft, Molecules, 2020, 25, 2647. 
K. Saito, T. Arai, N. Takahashi, T. Tsukuda and T. Tsubomura, J. Chem. Soc. Dalt. Trans., 2006, 4444-4448.

29 F. Brunner, A. Babaei, A. Pertegás, J. M. Junquera-Hernández, A. Prescimone, E. C. Constable, H. J. Bolink, M. Sessolo, E. Ortí and C. E. Housecroft, Dalt. Trans., 2019, 48, 446-460.

D. Rota Martir, A. K. Bansal, V. Di Mascio, D. B. Cordes, A. F. Henwood, A. M. Z. Slawin, P.

C. J. Kamer, L. Martínez-Sarti, A. Pertegás, H. J. Bolink, I. D. W. Samuel and E. ZysmanColman, Inorg. Chem. Front., 2016, 3, 218-235.

31 C. Li, R. Dickson, N. Rockstroh, J. Rabeah, D. B. Cordes, A. M. Z. Slawin, P. Hünemörder, A. Spannenberg, M. Bühl, E. Mejía, E. Zysman-Colman and P. C. J. Kamer, Catal. Sci. Technol., $2020,10,7745-7756$.

L. A. Van Der Veen, P. H. Keeven, G. C. Schoemaker, J. N. H. Reek, P. C. J. Kamer, P. W. N. M. Van Leeuwen, M. Lutz and A. L. Spek, Organometallics, 2000, 19, 872-882.

C. P. Casey and G. T. Whiteker, Isr. J. Chem., 1990, 30, 299-304.

S. M. Kuang, D. G. Cuttell, D. R. McMillin, P. E. Fanwick and R. A. Walton, Inorg. Chem., 2002, 41, 3313-3322.

S. Yanagida, M. Yoshida, W. M. C. Sameera, A. Kobayashi and M. Kato, Bull. Chem. Soc. Jpn., 2019, 92, 1684-1693.

S. Mutrofin, E. J. Chan, P. C. Healy, A. Marinelli, J. Ngoune, C. Pettinari, R. Pettinari, N. Somers, B. W. Skelton and A. H. White, Inorganica Chim. Acta, 2008, 361, 2365-2374.

Y. Ma, Y. Dong, P. She, S. Liu, M. Xie, Y. Yu, Y. Li, Q. Zhao and W. Huang, Adv. Opt. Mater., 2018, 6, 1801065.

K. Kubiček, S. Thekku Veedu, D. Storozhuk, R. Kia and S. Techert, Polyhedron, 2017, 124, $166-176$.

J. R. Kirchhoff, W. R. Robinson, D. R. Powell, A. T. Mckenzie, S. Chen and D. R. Mcmillin, Inorg. Chem., 1985, 24, 3928-3933.

P. C. J. Kamer, P. W. N. M. Van Leeuwen and J. N. H. Reek, Acc. Chem. Res., 2001, 34, 895904.

41 N. M. O'Boyle, A. L. Tenderholt and K. M. Langner, J. Comput. Chem., 2008, 29, 839-845.

42 W. J. Stevens, M. Krauss, H. Basch and P. G. Jasien, Can. J. Chem., 1992, 70, 612-630.

43 R. Ditchfield, W. J. Hehre and J. A. Pople, J. Chem. Phys., 1971, 54, 720-723.

44 P. C. Hariharan and J. A. Pople, Theor. Chim. Acta, 1973, 28, 213-222.

45 M. S. Gordon, J. S. Binkley, J. A. Pople, W. J. Pietro and W. J. Hehre, J. Am. Chem. Soc., 1982, 104, 2797-2803.

M. M. Francl, W. J. Pietro, W. J. Hehre, J. S. Binkley, M. S. Gordon, D. J. DeFrees and J. A. Pople, J. Chem. Phys., 1982, 77, 3654-3665.

47 W. J. Hehre, K. Ditchfield and J. A. Pople, J. Chem. Phys., 1972, 56, 2257-2261.

48 T. Yanai, D. P. Tew and N. C. Handy, Chem. Phys. Lett., 2004, 393, 51-57. 
49 Y. Zhang, M. Heberle, M. Wächtler, M. Karnahl and B. Dietzek, RSC Adv., 2016, 6, 105801105805 .

50 N. G. Connelly and W. E. Geiger, Chem. Rev., 1996, 96, 877-910.

51 Y. Zhang, P. Traber, L. Zedler, S. Kupfer, S. Gräfe, M. Schulz, W. Frey, M. Karnahl and B. Dietzek, Phys. Chem. Chem. Phys., 2018, 20, 24843-24857.

52 G. J. Kavarnos and N. J. Turro, Chem. Rev., 1986, 86, 401-449.

53 S. E. Braslavsky, Pure Appl. Chem., 2007, 79, 293-465.

54 C. Minozzi, A. Caron, J. C. Grenier-Petel, J. Santandrea and S. K. Collins, Angew. Chemie - Int. Ed., 2018, 57, 5477-5481.

55 J. D. Nguyen, E. M. D'Amato, J. M. R. Narayanam and C. R. J. Stephenson, Nat. Chem., 2012, 4, 854-859.

56 J. M. Kern and J. P. Sauvage, J. Chem. Soc. Chem. Commun., 1987, 546-548.

57 A. Kaeser, O. Moudam, G. Accorsi, I. Séguy, J. Navarro, A. Belbakra, C. Duhayon, N. Armaroli,

B. Delavaux-Nicot and J. F. Nierengarten, Eur. J. Inorg. Chem., 2014, 2014, 1345-1355.

58 C. K. Prier, D. A. Rankic and D. W. C. MacMillan, Chem. Rev., 2013, 113, 5322-5363.

59 R. Marion, F. Sguerra, F. Di Meo, E. Sauvageot, J. F. Lohier, R. Daniellou, J. L. Renaud, M. Linares, M. Hamel and S. Gaillard, Inorg. Chem., 2014, 53, 9181-9191.

60 K. Suzuki, A. Kobayashi, S. Kaneko, K. Takehira, T. Yoshihara, H. Ishida, Y. Shiina, S. Oishi and S. Tobita, Phys. Chem. Chem. Phys., 2009, 11, 9850-9860.

61 N. Y. Chen, L. M. Xia, A. J. J. Lennox, Y. Y. Sun, H. Chen, H. M. Jin, H. Junge, Q. A. Wu, J. H. Jia, M. Beller and S. P. Luo, Chem. - A Eur. J., 2017, 23, 3631-3636.

62 C. L. Linfoot, M. J. Leitl, P. Richardson, A. F. Rausch, O. Chepelin, F. J. White, H. Yersin and N. Robertson, Inorg. Chem., 2014, 53, 10854-10861.

63 M. Iwamura, S. Takeuchi and T. Tahara, J. Am. Chem. Soc., 2007, 129, 5248-5256.

64 A. Poater, B. Cosenza, A. Correa, S. Giudice, F. Ragone, V. Scarano and L. Cavallo, Eur. J. Inorg. Chem., 2009, 2009, 1759-1766.

65 H. Clavier and S. P. Nolan, Chem. Commun., 2010, 46, 841-861.

66 J. McCall, D. Bruce, S. Workman, C. Cole and M. Richter, Anal. Chem., 2001, 73, 4617-4620.

67 Q. Zhang, Q. Zhou, Y. Cheng, L. Wang, D. Ma, X. Jing and F. Wang, Adv. Funct. Mater., 2006, 16, 1203-1208.

68 Y. Huang, E.-L. Hsiang, M.-Y. Deng and S.-T. Wu, Light Sci. Appl., 2020, 9, 105. 


\section{TOC Graphic}

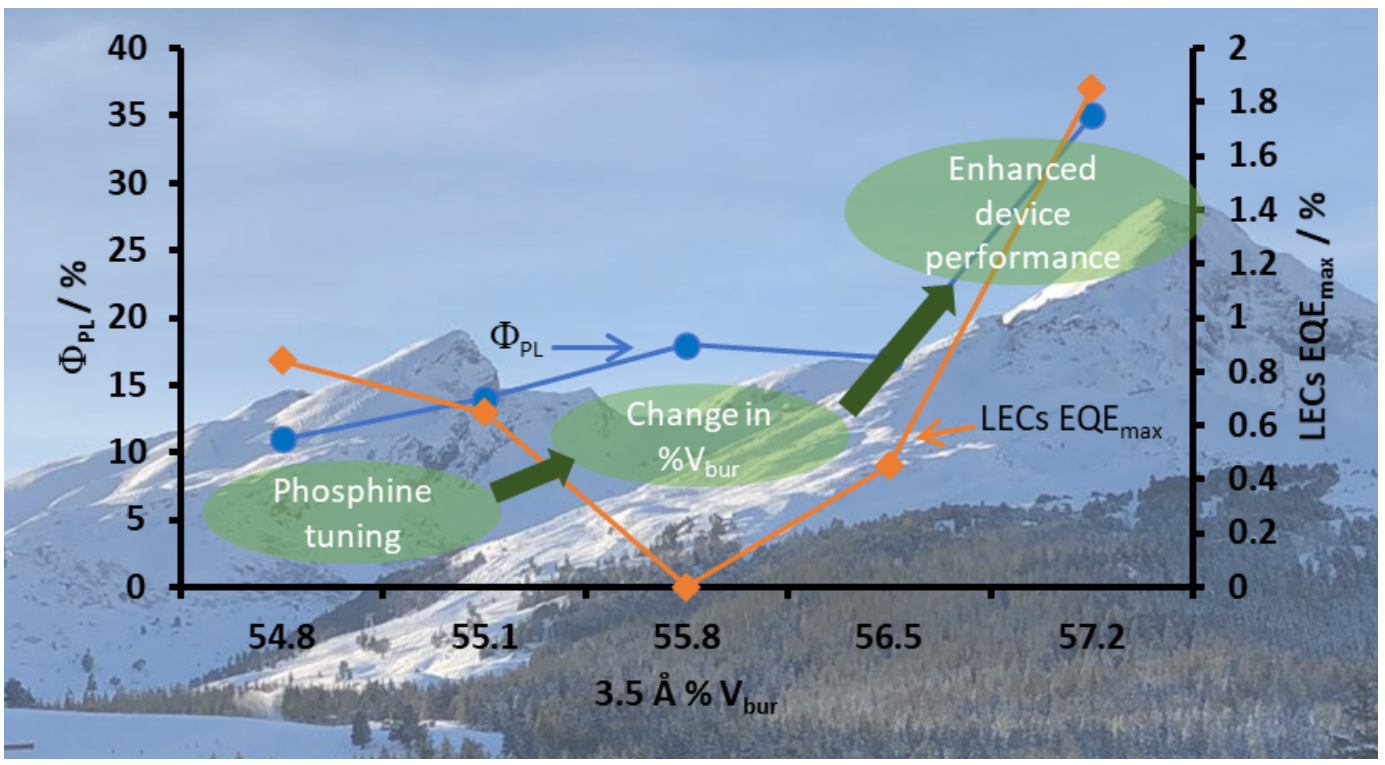

